\title{
La ultrasonografía endovaginal en obstetricia
}

\author{
Francisco José Sales Puccini*; Alfredo Ariza Machado**
}

RESUMEN: Este trabajo tiene como objetivo comprobar la aplicación de la US endovaginal (USE) en obstetricia, sus beneficios e inconvenientes en relación con la técnica abdominal, la utilidad diagnóstica en alteraciones embrionarias, fetales, ovulares y maternas durante el embarazo, además de un análisis del futuro de la (USE) en el plano investigativo.

Para este estudio se seleccionaron pacientes entre abril de 1990 y octubre de 1991 de la Unidad de Alto Riesgo Obstétrico del Departamento de Ginecología y Obstetricia del Hospital Simón Bolívar que necesitasen un estudio ecográfico integral (US Abdominal y Endovaginal), según los parámetros antes mencionados, y se citaron a un programa secuencial de estudio ecográfico correlacionado con los hallazgos clínicos y paraclínicos de cada caso. Siendo este programa uno de los resultados de la política académica de nuestro postgrado de gineco-obstetricia consistente en vincular al servicio tecnología foránea mediante la colaboración de instituciones privadas.

En dicho estudio se utilizó un ultrasonógrafo PHILIPS de 256 grises de resolución con un transductor lineal de 4 MHZ, un sectorial de foco medio de $3.5 \mathrm{MHZ}$, y un endovaginal de $7.5 \mathrm{MHZ}$ con un ángulo de visión de $90^{\circ}$. Las gráficas se imprimieron en un printer de papel termosensible de alta resolución. Se efectuó además como soporte teórico una revisión bibliográlica de más de 100 referencias entre $1987-1991$ sobre temas como: los usos de la USE en el primer trimestre normal y patológico, su correlación con los niveles séricos de BHCG, el papel de la USE en el diagnóstico precoz de anomalías congénitas, su uso en la incompetencia cervical y placenta previa.

Todo esto compendiado en 8 capítulos e ilustrado con un reporte gráfico de 60 ilustraciones sobre nuestra experiencia en cada uno de estos temas.

Después de un año de estudios ecográficos correlacionados (clínico-imagenológico), no dudamos en concluir que la US Endovaginal marca una nueva era en el diagnóstico precoz’en obstetricia y por ende en la terapéutica de la obstetricia moderna.

PALABRAS CLAVES: Ultrasonografía endovaginal, alteraciones embrionarias, fetales y ovulares.

SUMMARY: The objective of this study is to verify the application of Endovaginal US (EVUS) in obstetrics, its benefits and inconveniences in relation to the abdominal technique, the diagnostic advantage in embrionary, fetal, ovulary and maternal alterations during pregnancy, besides an analysis of the future of EVUS at the research level.

For this study, patients needing an integral ecographic study (Abdominal and Endovaginal US) according to the above-mentioned parameters, were chosen from the High Obstetric Risk Unit at the Simón Bolívar Hospital in a period between april 1990 and october 1991. They were required to attend a sequential program consisting of an ecographic study in correlation to clinical and paraclinical findings of each case. This program is one of the results of the academic policy in our gynecology \& obstetrics postgraduate program, aimed towards incorporating foreign technology to the service, with the assistance of private institutions.

A 256 grey resolution PHILIPS ultrasonic linear $4 \mathrm{MHZ}$ transducer, a $3.5 \mathrm{MHZ}$ mean focus, and a $7.5 \mathrm{MHZ}$ endovaginal having a $90^{\mathrm{a}}$ angle vision was used in this study. The graphs were printed in a high resolution thermosensitive paper printer. As a theoretic support, a bibliographic revision of over 100 references was also carried out from 1987-1991, on such subjects as: EVUS applications in the first normal and pathologic quarter, its correlation to seric levels of BHCE, the role of EVUS in early diagnosis of congenital anomalies, its use in cervical incompetence and previous placenta.

All this is submitted here in eight chapters, and illustrated with a graphical report in 60 illustrations based on our experience in each one of these cases.

After one year of correlated ecographic (clinical-imaginative) studies, we do not hesitate when concluding that Endovaginal US marks a new era in early obstetric diagnosis and therefore, in modern obstetric therapeutics.

KEY WORDS: Endovaginal ultrasonography, embrionan, fetal and ovulary alterations. 


\section{Consideraciones generales}

La ultrasonografía endovaginal (USE) es una nueva e interesante modalidad de técnica ultrasonográfica, que rápidamente está ganando adeptos entre los obstetras. La US endovaginal ha tenido un avance realmente excepcional. La USE fue inicialmente descrita como una técnica útil para la monitorización del desarrollo folicular en pacientes infértiles a quienes se les había hecho una estimulación hormonal.

Actualmente las cosas están cambiando. El cuerpo médico que trabaja con USE ha encontrado día a día más utilidades en la práctica ginecobstétrica; además de la aceptación creciente por parte de las pacientes a este método ultrasonográfico ya que es preferido por muchas de ellas por evitarse la incomodidad de la vejiga llena; lo que ha hecho de la USE un método de petición frecuente.

Además de lo anterior, la tendencia actual en la fabricación de transductores endovaginales está encaminada a reducir el diámetro de los mismos en la medida que aumentan su ángulo y profundidad de visión, lo que hace más sutil y menos incómoda su manipulación. En vista de lo anterior están naciendo nuevas posibilidades de apliación diagnóstica, entre ellas la evaluación más integral del primer trimestre del embarazo y sus complicaciones, la valoración más temprana y precisa del embarazo tubárico, el mejor análisis del cervix y del segmento uterino inferior de la embarazada en el segundo y tercer trimestre por citar los más relevantes.

De ninguna manera éste es un estudio sobre la técnica endosonográfica, es más bien una revisión sobre la aplicación de la US endovaginal en obstetricia, sus beneficios e incovenientes, los usos más actuales y un reporte gráfico preliminar sobre nuestra experiencia en estos aspectos, además de un análisis comparativo con la técnica abdominal, intentando de esta manera proporcionar al lector un buen punto de referencia para la mejor interpretación clínica que este método de imagen diagnóstica pueda arrojar sobre la problemática de nuestro paciente, ayudando a valorar precisa y racionalmente este recurso dentro de nuestra práctica médica diaria.

\section{Beneficios e inconvenientes de la US endovaginal y su correlación con la visión transabdominal}

Existen numerosas series en la literatura mundial encaminadas a comparar las ventajas con las desventajas de estos dos métodos ecográficos (1-5), dando un carácter descriminatorio y de exclusión, según se incline la balanza del autor.

Nuestra tendencia es más ecléctica, en la medida en que se le reconoce a cada método sus beneficios e inconvenientes, de tal manera que al tenerlos bien claros, su complementación dará una visión más amplia y precisa de la problemática clínica de nuestro paciente.

\section{Beneficios de la US endovaginal}

A. La proximidad del transductor al órgano en observación; pemite una mayor resolución de la imagen, sumando a esto el uso de mayores frecuencias como 5 y 7.5 Mhz con

\footnotetext{
* Residente de IV año de Ginecología y Obstetricia de la Escuela Colombiana de Medicina (E.C.M.).

** Profesor asistente del área bioclínica y postgrado de la E.C.M. y docente asignado a la coordinación del servicio de alto riesgo obstétrico del Hospital Simón Bolívar.
}

ángulos de visión hasta de $240^{\circ}$ permiten una calidad óptima en la observación del órgano en estudio (Gráfica I.2).

B. No se requiere una "ventana sónica" como lo es la vejiga llena, que además de ser incómoda para las pacientes, en determinados casos (cuando hay sobredistensión, por ejemplo) distorsiona la imagen, perdiéndose así la exactitud en observar la verdadera relación anatómica entre los órganos; otro ejemplo es la relación que guarda el cérvix y el segmento uterino inferior con las partes ovulares de un embarazo, detalles anexiales como quistes de ovario, cuerpo lúteo o folículos en crecimiento (4) (Gráfica I.2).

C. Disminuye la posibilidad de observaciones insatisfactorias o de mala calidad por tejido adiposo, ya que el transductor está más cerca del órgano "Diana" (2).

D. Elimina casi por completo las llamadas "zonas ciegas", que se presentan en la ecografía abdominal por la interposición de otros tejidos y/o estructuras como el hueso o el gas intestinal, siendo de mucha utilidad para la valoración ultrasonográfica de los anexos (2).

E. El estudio de la patología uterina ha encontrado en la endosonografía un aliado muy importante. La visión endometrial, miometrial y cervical. presenta patrones ultrasonográficos de gran ayuda en el diagnóstico de la patología uterina en general (2).

F. La US endovaginal facilita la observación y diagnóstico de eventos que en otras circunstancias serían casi imposibles de visualizar como:

- Saco gestacional desde la 4a. semana post-menstruación (2a. semana gestacional).

- Latido cardíaco a partir de la 5a. a 6a. semana post menstruación (3a. a 4a. semana gestacional).

- La visualización bastante clara de la anatomía embrionaria.

- El análisis de la cantidad, calidad, regularidad y localización del trofoblasto desde etapas muy tempranas de la gestación.

- La observación relativamente fácil de la vesícula vitelina para su estudio y medición, estableciendo hallazgos compatibles con un pronóstico determinado de viabilidad gestacional; además del estudio de la forma y características estructurales del saco gestacional con el mismo fin (1-5) (Figuras I.1, I.2, I.3, y I.4).

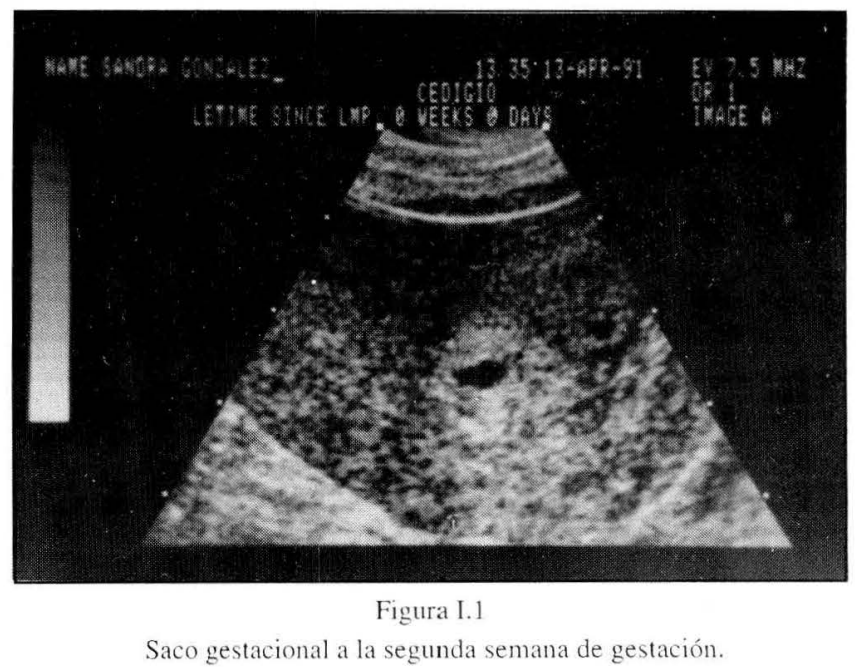




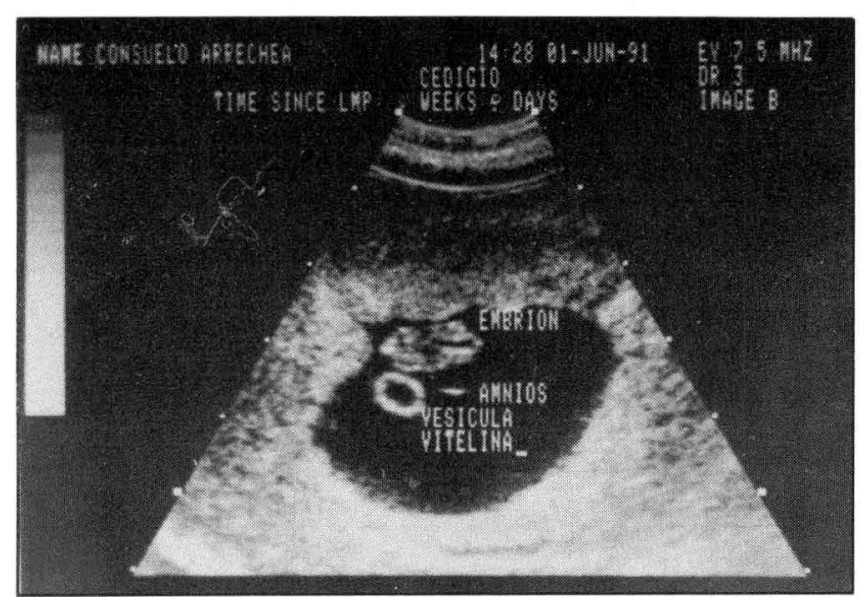

Figura I.2

En esta imagen se observa la vesícula vitelina, el amnios y el embrión entre la quinta y sexta semana de edad gestacional.

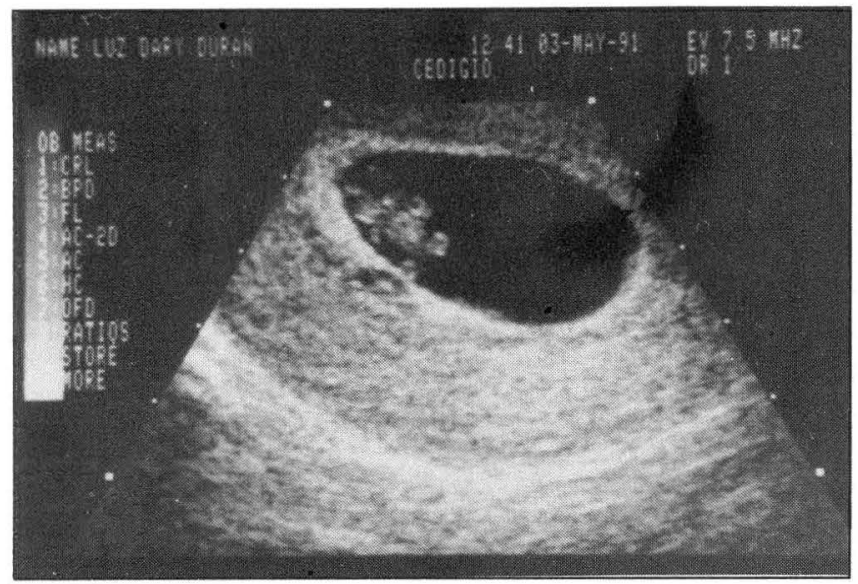

Figura 1.3

La visualización de la cabeza, el cuerpo fetal y los botones embrionarios de las cuatro extremidades a la 6a. semana de gestación. Se observa también el engrosamiento del trofoblasto en el polo embrionario. lo que en un futuro será la placenta.

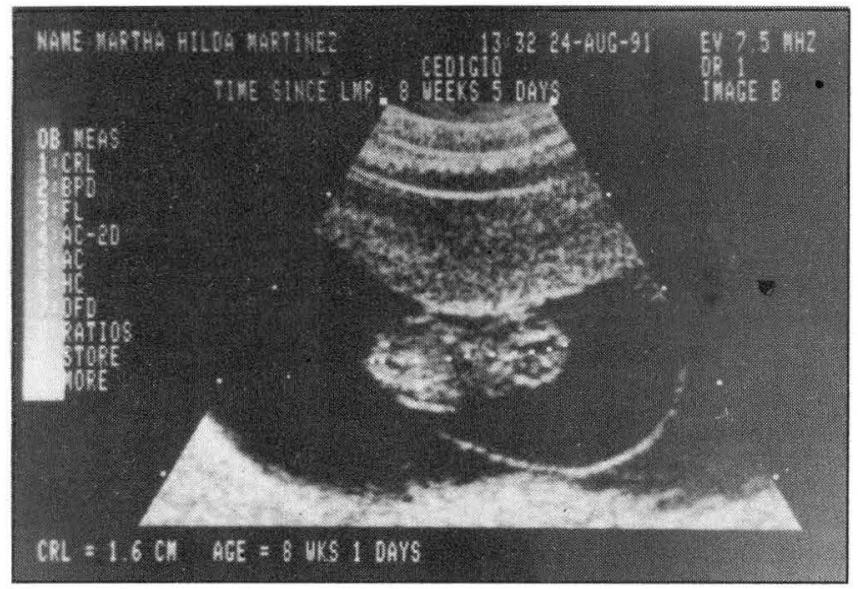

Figura I.4

Se observa la correcta medición de la longitud cráneo caudal de un embrión de 9 semanas, recubierto por sus bolsas amnióticas sin fusionar.
G. Análisis de tejidos anexiales como: folículos, quistes de ovario, morfología ovárica en general, colección líquida en las trompas o embarazo tubárico $(10,12)$.

H. La imagen ultrasonográfica endovaginal colabora eficazmente al esclarecimiento diagnóstico de patologías como la endometriosis, la incompetencia cervical y embarazo o el grado de placenta previa, entre otras. La US endovaginal además de ser diagnóstica, permite bajo su guía procedimientos invasivos de gran ayuda como punciones y biopsias (11) (Gráfica I.1).

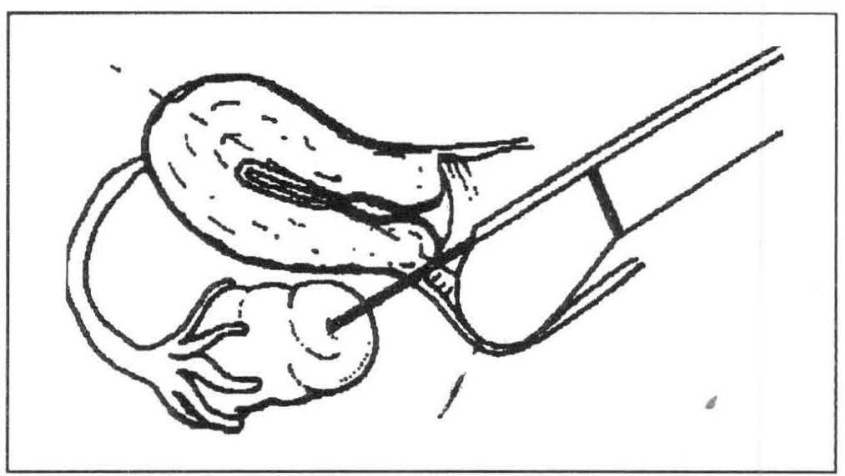

Gráfica I.1:

Esta gráfica muestra de forma esquemática la manera de realizar procedimientos invasivos por US Endovaginal. En este caso específico se esquematiza una luteolisis asistida.

\section{Inconvenientes de la US endovaginal}

Uno de los inconvenientes más notorios de la US endovaginal es no permitir la visualización de estructuras lejanas dentro de la misma pelvis.

La obtención de una imagen unidireccional con amplitud limitada, hace imposible obtener la verdadera imagen panorámica que se logra con la ultrasonografía abdominal; claro que los avances tecnológicos en la fabricación de los nuevos modelos de transductores endovaginales, están encaminados a reducir éste inconveniente. Es así como ahora existen transductores de visión anular con ángulos de visión hasta de $150^{\circ}$ y $240^{\circ}$

A pesar de la tendencia de los fabricantes en producir transductores más delgados, los actuales grosores (aunque menores que sus antecesores) pueden en algunos casos limitar su uso por incomodidad y/o dolor $(5,6,8,9)$, por ejemplo: en

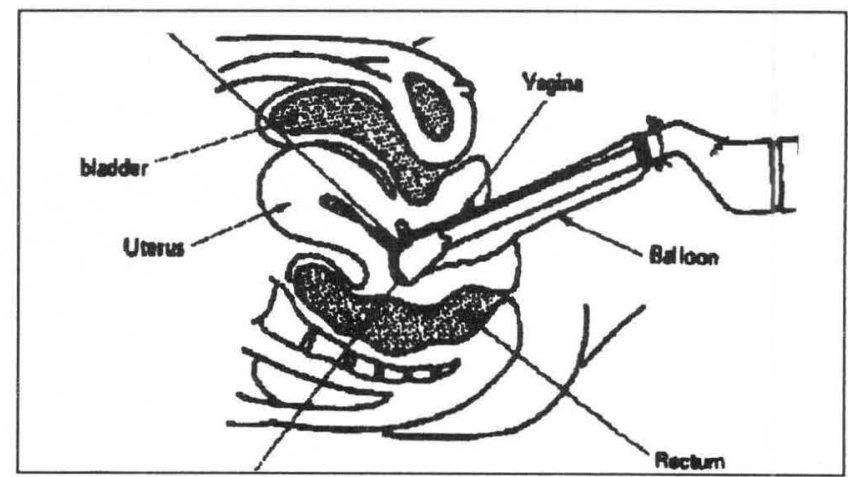

Gráfica 1.2:

En esta gráfica ilustramos la relación que guarda un transductor endovaginal y su nientes de la ultrasonografía endovaginal, ampliamente explicados al principio de este capítulo. 
mujeres vírgenes con estenosis vaginal o menopáusicas (Gráfica I.2 y Figuras: I.5, I.6, I.7 y I.8).

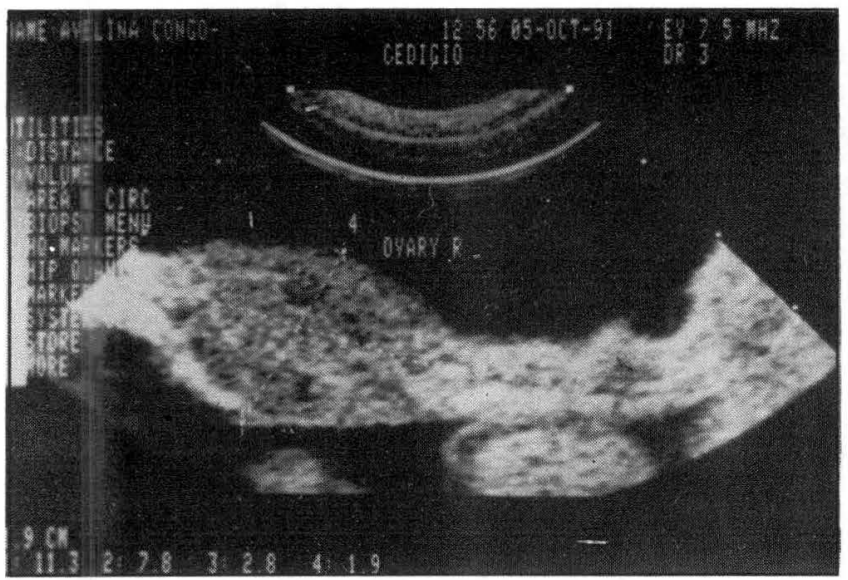

Figura I.5

Ovario normal con los ligamentos útero ovárico e infundíbulo pélvico.

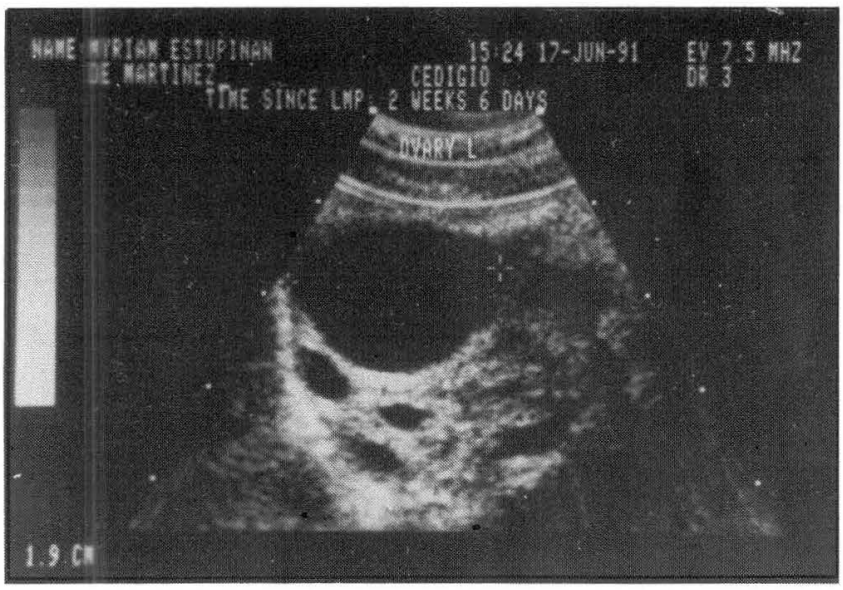

Figura I.6

Quiste folicular en pre-ruptura, con un diámetro de $19 \mathrm{~mm}$, se observa alrededor folículos atrésicos.

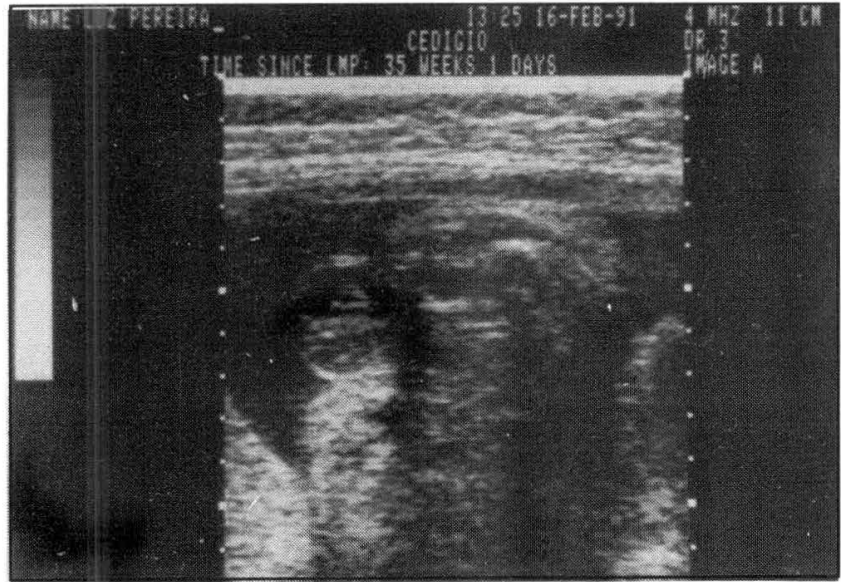

Figura I.7

Testículos fetales a la semana 35 , visión abdominal con un transductor lineal de $4 \mathrm{MHZ}$

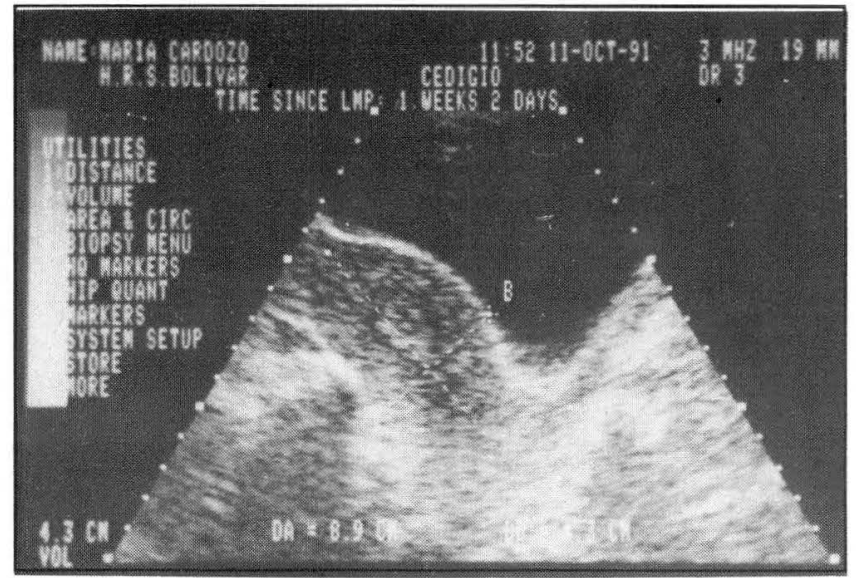

Figura I.8

Evaluación panorámica del miometrio y endometrio con un transductor sectorial de $3 \mathrm{MHZ}$.

\section{Usos actuales de la US endovaginal}

En numerosas series revisadas, la US endovaginal es recomendada como una técnica complementaria de diagnóstico, apoyada en bases clínicas (historia clínica completa, sintomatología y examen físico) y otros estudios paraclínicos entre los cuales se encuentra la ecografía abdominal convencional.

La US endovaginal estuvo inicialmente dirigida a la reproducción humana (Foliculogramas para el control del crecimiento folicular) y en programas de reproducción asistida. Actualmente existen varios niveles diagnósticos en los que su uso es de gran utilidad:

El primero es en obstetricia: En este nivel diagnóstico la US endovaginal es de gran importancia en:

A. El control de la gestación en el primer trimestre. Se sabe que existen datos cuantitativos en el diagnóstico precoz del embarazo por US endovaginal como la visualización de algunas estructuras una a dos semanas antes que con la ecografía convencional, como son:

Saco gestacional a la cuarta semana post-menstruación. (2a. semana gestacional) (Figura II.1).

- Vesícula vitelina a la quinta semana post menstruación. (3a.-4a. gestacional).

- Embrión a la quinta semana post menstruación. (3a.-4a. gestacional).

- Frecuencia cardíaca entre la 5a. y 6a. semana. (4a- 6a. gestacional).

Existen otros informes que revisan comparativamente los niveles de BHCG y la aparición del embrión por US endovaginal, lollaman "zona discriminatoria" de BHCG, que correlaciona la observación endovaginal del embrión con niveles de $B H C G$, siendo su parámetro mínimo entre 750 a $1500 \mathrm{mUI} / \mathrm{ml}$ (Primer Standard Internacional) dependiendo de la capacidad de resolución del equipo, en dicha franja se puede observar perfectamente el saco gestacional $(1,2,4)$. (Numeral IV y Figuras II.2a, II.2b y II.2c).

B. El control de la gestación normal y patológica primordialmente en el primer trimestre, por ejemplo; es de gran utilidad para el diagnóstico de entidades como el embarazo ectópico, aborto o sacos anembrionados, entre otras. 


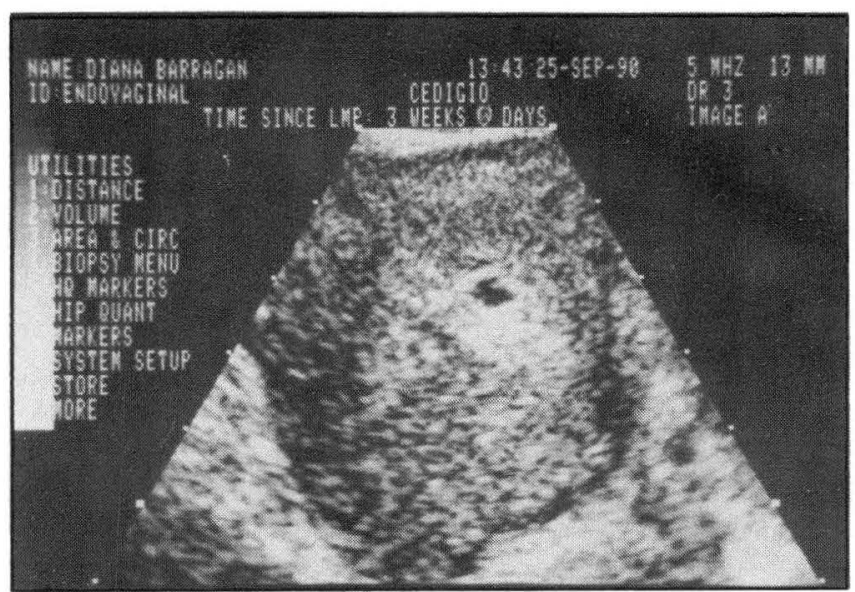

Figura II.1

Embarazo de dos semanas concepcionales, 3 semanas x FUR con $\beta$ HCG de $805 \mathrm{mUI} / \mathrm{ml}$.

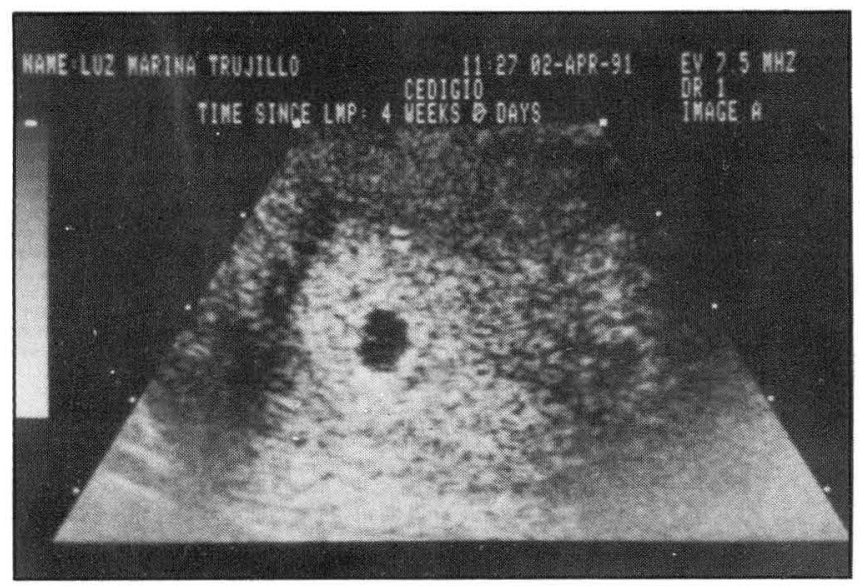

Figura II.2b

El mismo día por "USE" se observa saco gestacional de 2 semanas concepcionales, la B HCG: $1.064 \mathrm{mUI} / \mathrm{ml}$.

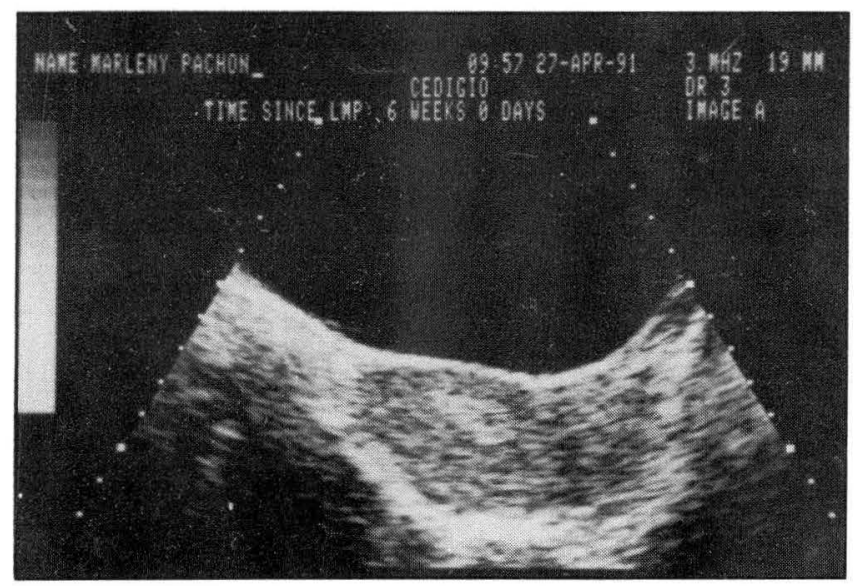

Figura II. 3a

Paciente con 6 semanas de amenorrea, por US abdominal se observa endometrio oval, ecogénicamente compatible con un endometrio premenstrual.

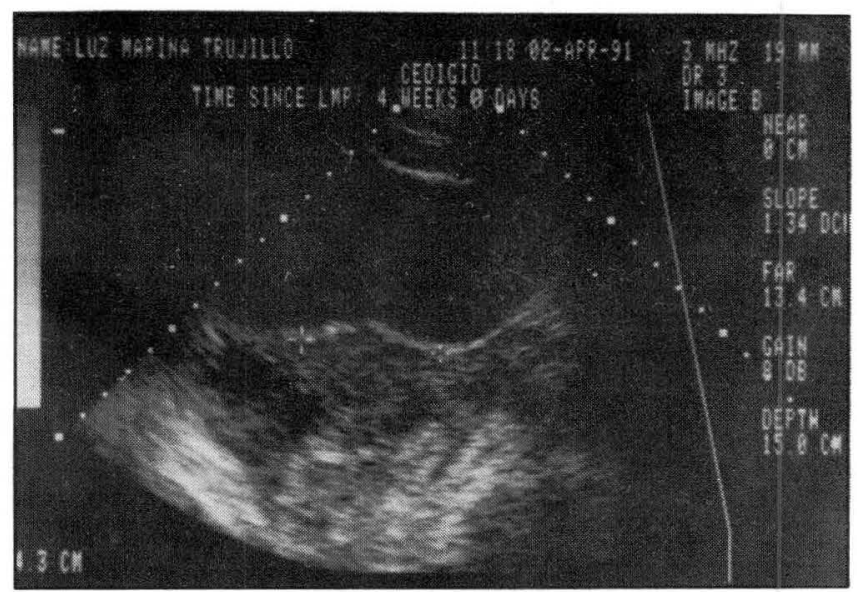

Figura II.2a

Paciente de 22 años con dolor pélvico y amenorrea de 4 semanas, la US abdominal revela útero de forma y ecogenicidad normal con un endometrio engrosado.

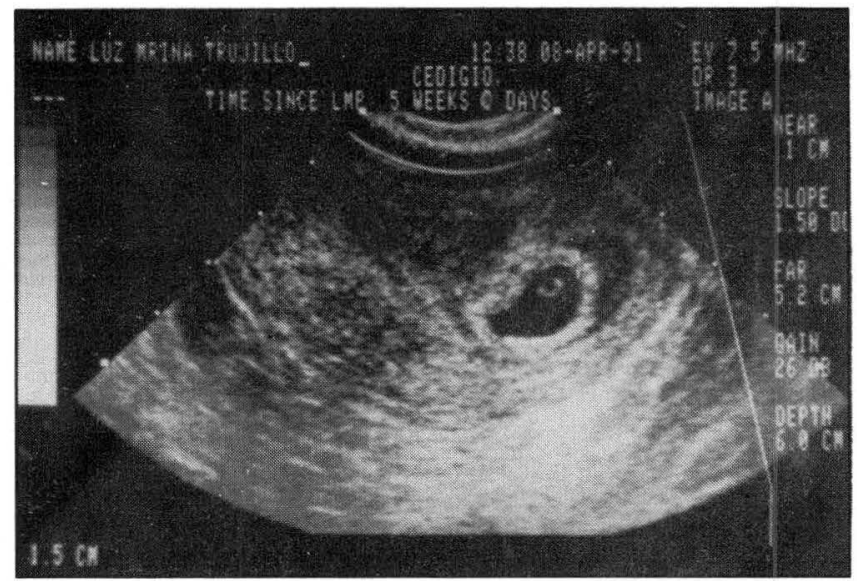

Figura II.2c

Siete días más tarde por "USE" se observa claramente saco gestacional y vesícula vitelina, el nivel de la fracción $\beta$ de $\mathrm{HCG}$ fue de $1.830 \mathrm{mUI} / \mathrm{ml}$.

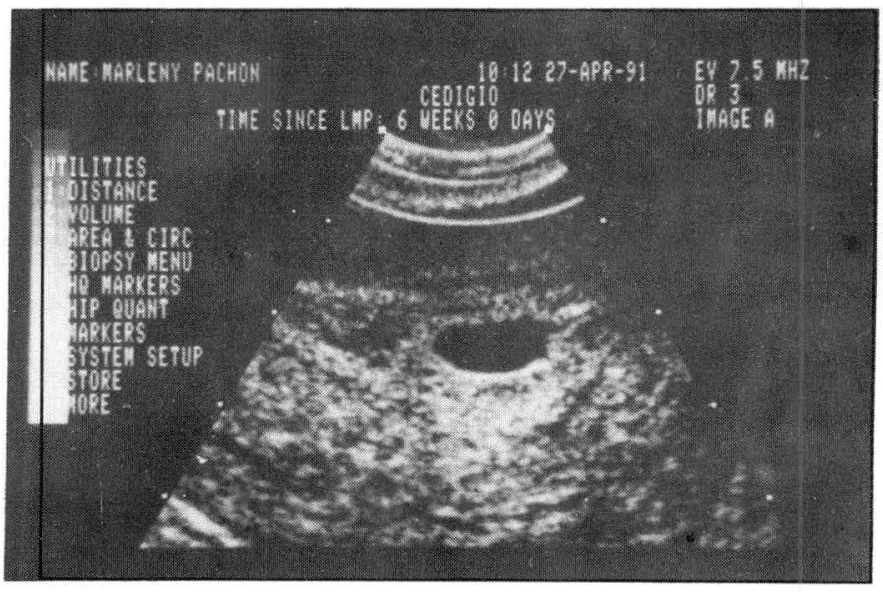

Figura II 3b.

El mismo día se realiza "USE", encontrándose saco gestacional irregular, sin embrión ni vesícula vitelina; la paciente presentó un aborto anembrionado una semana después. 


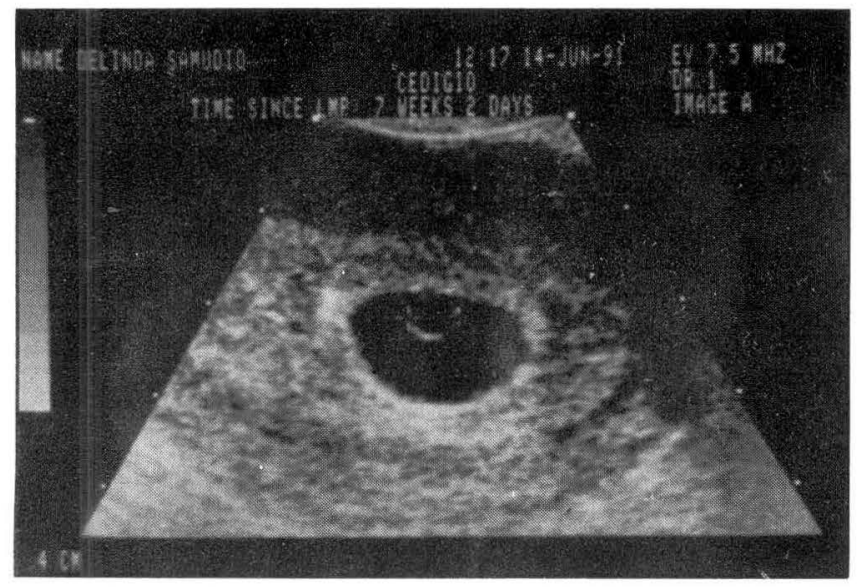

Figura II. $4 \mathrm{a}$

El mismo día por "USE" se observa saco gestacional normal, con vesícula vitelina de forma tamaño y ecogenicidad normal.

(Figuras: II.3a, II. 3b, II.4a y II.4b.).

En el segundo y tercer trimestre la US endovaginal es útil en el estudio y diagnóstico de las pacientes embarazadas con incompetencia cervical, en la clasificación de la placenta previa y en los casos de procúbito o procidencia del cordón.

Algunos obstetras están renuentes a su uso en los casos de incompetencia cervical y placenta previa en específico, por la explícita recomendación clásica de evitar la manipulación de la vagina y el cérvix en estos casos, con el fin de no provocar en la paciente un abundante sangrado o una indeseada actividad uterina. Sin embargo, se ha precisado que con un adecuado manejo del transductor se puede hacer un examen endovaginal sin ninguna complicación (Numerales VII y VIII).

Además de lo anterior, hay que tener en cuenta que se eliminan las falsas interpretaciones que sobre placenta previa se han visto en la ecografía abdominal ya que esta última introduce distorsiones en la imagen del segmento uterino inferior, principalmente por el desplazamiento que sufre el útero por una vejiga sobredistendida.

El segundo nivel: Se relaciona con el estudio de estructuras específicas de la pelvis:

A. En útero y endometrio: Para el Dx de miomatosis, adenomiosis, hiperplosia endometrial, fases proliferativa y secretora del ciclo $(7,9,10)$ (Figuras II.5a, II.5b, II.5c y II.5d).

B. En trompas uterinas: Para el Dx de hidrosalpings, abscesos tuboováricos, y masas anexiales en general (9).

C. En ovarios: para el control del crecimiento folicular, el Dx y control de quistes ováricos, cuerpo lúteo y morfología ovárica en general $(5,6,12,17)$ (Figuras: I.6, II.6).

D. En vejiga se pueden realizar pruebas de volumen intravesical pre y post miccional, valoraciones anatómicas post-operatorias en cirugía de incontinencia urinaria entre otras $(3,8)$.

El tercer nivel: tiene que ver con la introducción de la "USE" como parte del estudio necesario en el estadiaje y clasificación de:

A. Carcinoma de cérvix $(6,12)$.

B. Carcinoma de endometrio $(7,10)$.

C. Tamizaje en la identificación de las pacientes con posible Cáncer incipiente de ovario $(5,13,14,17)$.

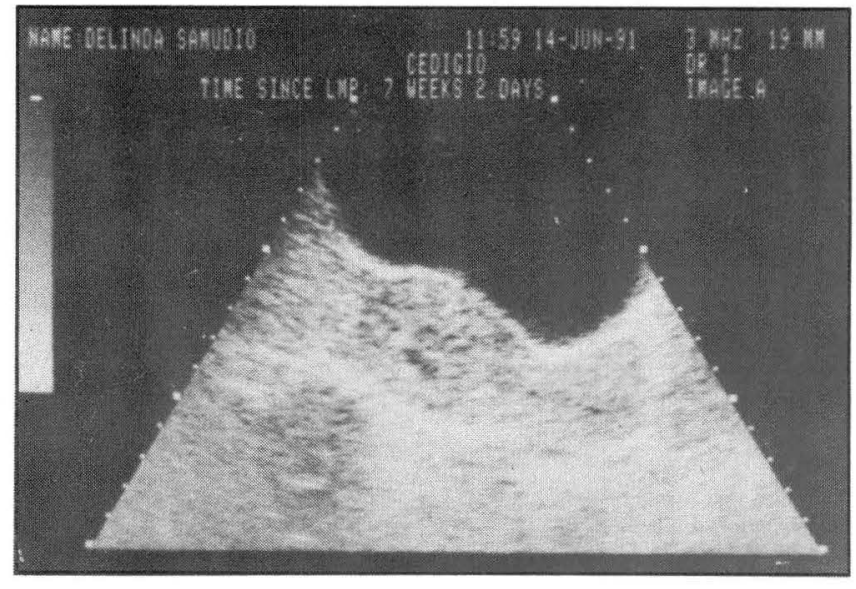

FiguraII.4b

Paciente con 7 semanas x FUR con B HCG de $1.250 \mathrm{mUI} / \mathrm{ml}$, útero de tamaño y ecogenicidad normal.

D. Tumoraciones uterinas y cuerpos extraños como D.I.U. $(9,10,15)$ (Figuras II.7, II.8a, II.8b).

E. Patología benigna de trompas uterinas $(9,16)$.

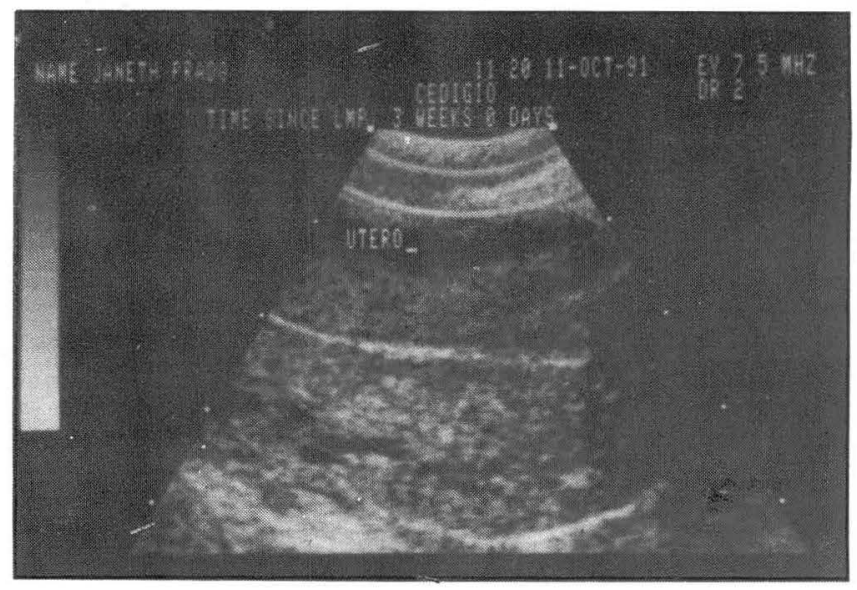

Figura II.5a

Línea endometrial ecorrefrigente, gruesa y homogénea, corresponde a la fase proliferativa de ciclo.

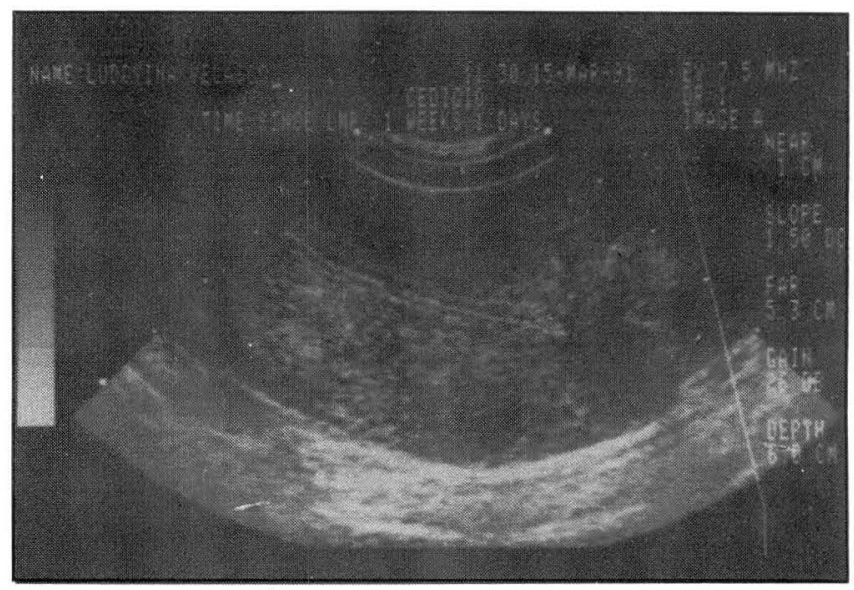

Figura II.5b

Triple línea endometrial estrechas y paralelas entre sí, mostrando la cavidad virtual del endometrio, imagen característica de un endometrio proliferativo avanzado (Grado I, según Kurjak). 


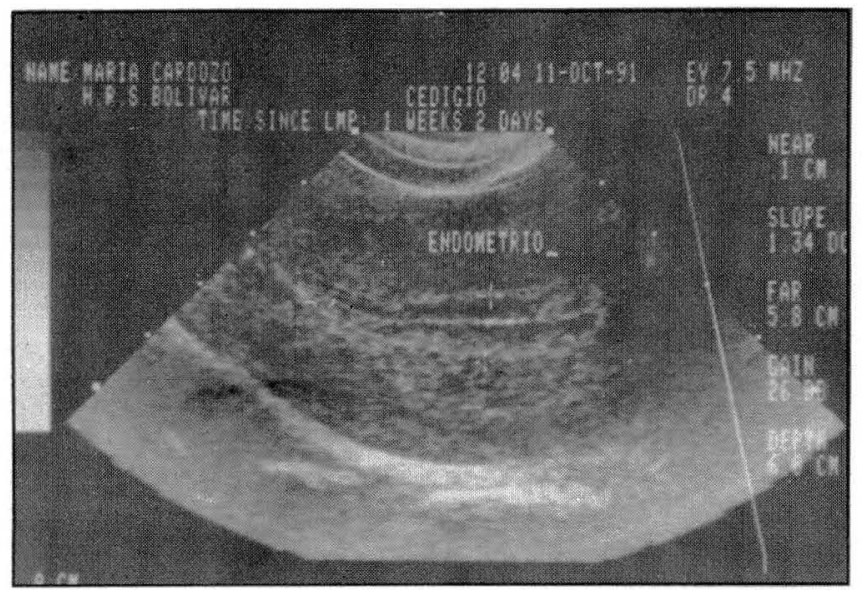

Figura II.5c

Doble línea oval divididas en mitades de un grosor aproximado a $9 \mathrm{~mm}$, característico del período peri-ovulatorio. (Grado II, según Kurjak).

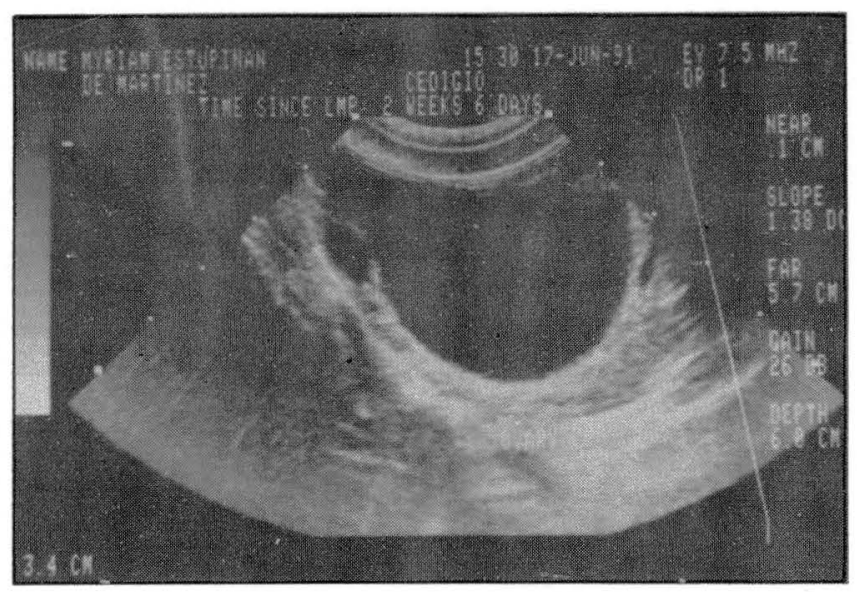

Figura II.6

Quiste de $34 \mathrm{~mm}$, paciente con síndrome de no ruptura folicular (síndrome LUV).

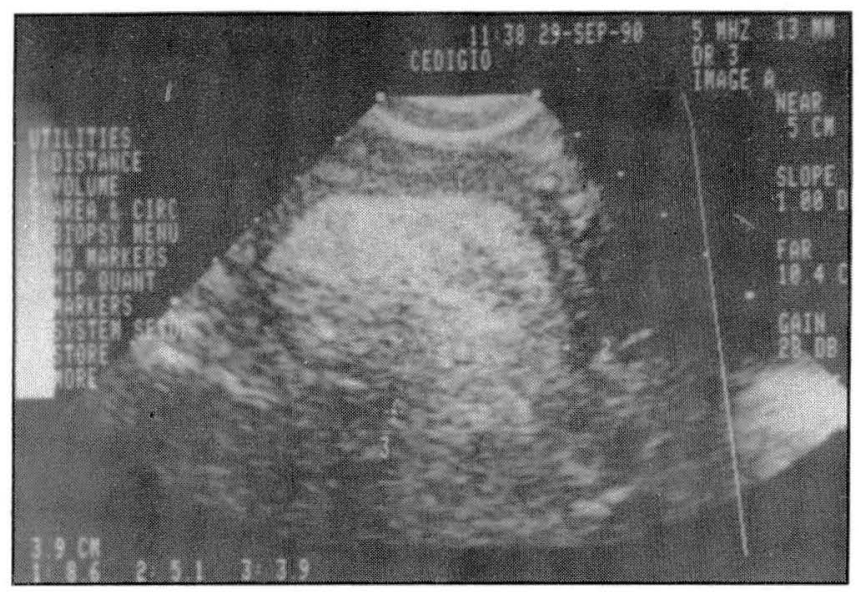

Figura II.8a

Paciente de 65 años con un gran mioma (zona ecorrefrigente central), alrededor se observa el miometrio adelgazado.

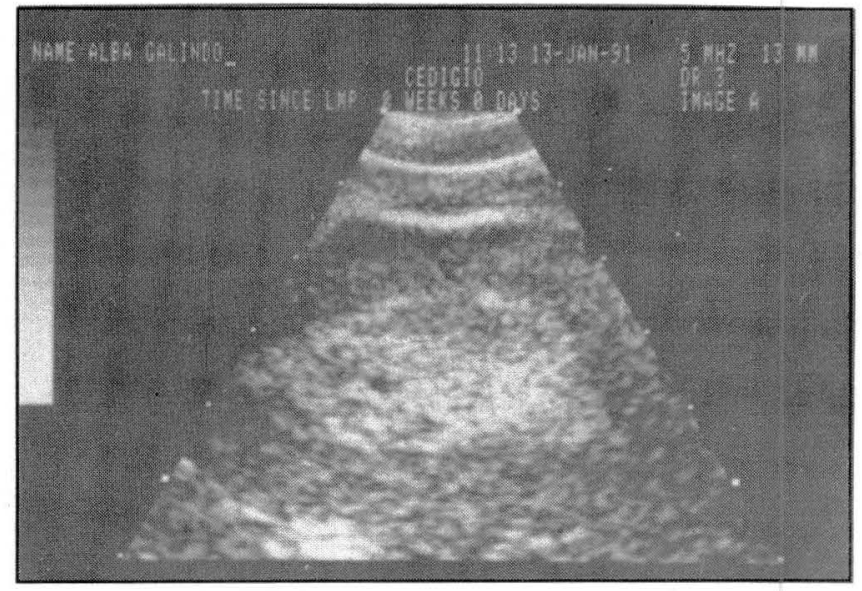

Figura II.5d

Endometrio de ecogenicidad difusa y mixta característico de la fase premenstrual. (Grado III, según Kurjak).

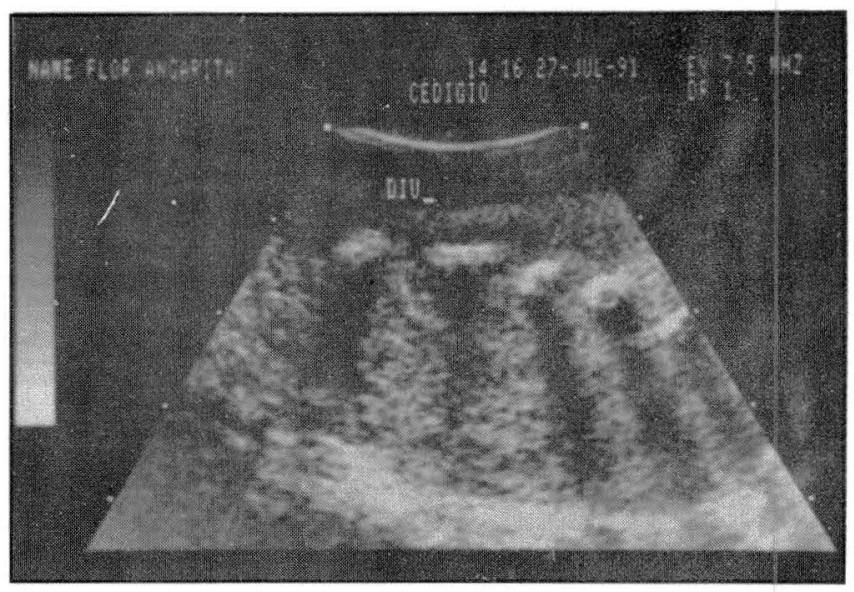

Figura II.7

Imagen de un DIU tipo asa de lipes por US endovaginal.

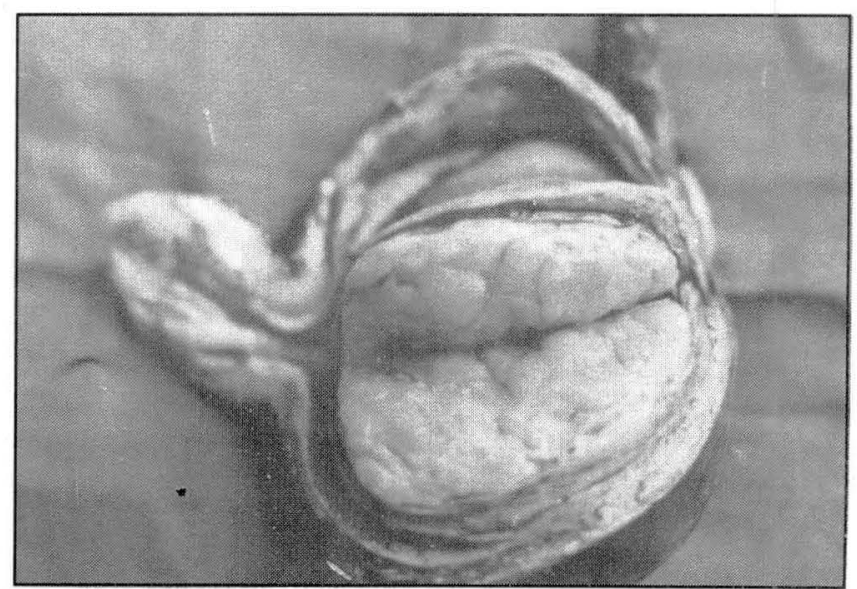

Figura II.8b

Pieza quirúrgica de dicho mioma donde se observan las mismas características anteriores. 


\section{El papel de la US vaginal en la supervisión tempra- na del primer trimestre normal}

La US endovaginal juega un papel importante en la vigilancia de un embarazo normal en su primer trimestre. Esta vigilancia se basa en la observación morfológica progresiva según la edad gestacional de las estructuras fetales y ovulares como: saco gestacional, vesícula vitelina, membranas amnióticas y morfología embrionaria. Además diagnosticar si el sitio de implantación del saco es compatible o no con la viabilidad del embarazo.

En definitiva, todos estos estudios pretenden supervisar el estado de normalidad de un embarazo en su primer trimestre y están encaminados a establecer pronósticos que sin duda alguna serán cada vez más exactos.

\section{La visualización del saco gestacional}

El saco gestacional es visible a partir de la cuarta semana postmenstruación (2a. semana postmenstruación). En esta edad la decidua es característica y fácil de observar, ya que la cavidad endouterina aparece como una línea fina y fuertemente hiperecogénica. El trofoblasto crea alrededor del saco un área ecogénicamente más clara y muy uniforme (1-3) (Figura II.1).

El saco gestacional crece rápidamente alcanzando un centímetro entre la quinta y la sexta semana tomando entonces su forma oval tan característica. Hacia la octava semana el trofoblasto presenta una zona asimétrica y más engrosada que corresponde al coriom frondoso, el cual será la futura placenta (4).

En todas estas semanas se pueden ir observando de forma detallada todas las estructuras anteriormente descritas, de tal forma que el ecografista se va haciendo una imagen global y progresiva del desarrollo del embrión (4) (Figuras: II.2a, II.2b, II.2c).

Estas imágenes cronológicas han sido comparadas en varios estudios con niveles séricos de BHCG encontrándose en promedio en casi todos estos estudios que los sacos gestacionales intrauterinos más pequeños que fueron visualizados median $2 \mathrm{~mm}$ de diámetro y se correlacionaban con unos niveles de $B H C G$ de $142 \mathrm{mUI} / \mathrm{ml}$ aproximadamente (Primer Standard Internacional) (5).

Establecieron también que todos los embriones con concentraciones de BHCG iguales o superiores a las $300 \mathrm{mUI} / \mathrm{ml}$ fueron clara y correctamente identificados $(5,6)$.

Estos estudios han servido para establecer una rata de incremento exponencial de la concentración de BHCG en suero materno de $1.7 \mathrm{mUI} / \mathrm{ml}$ día, en estasedades gestacionales tempranas $(5,7)$.

\section{El saco gestacional y su relación con la viabilidad del embarazo}

Durante el período embrionario, la identificación ultrasonográfica del latido cardíaco es el principal determinante de la presencia de la vitalidad de un embrión. Cuando se demuestra por ultrasonido convencional la presencia de saco gestacional intrauterino sin un embrión en estas primeras semanas de gestación, la diferenciación entre un embarazo normal y uno anormal o potencialmente no viable, es muy difícil (8-10).

El enfoque tradicional consiste en repetir los exámenes ultrasonográficos convencionales de forma seriada hasta poder evaluar el crecimiento del saco gestacional. De esta forma la ausencia de un embrión o el crecimiento inadecuado del saco indicaba un aborto no detectado o un embarazo anembrionado (8-10).

Hoy en día se han elaborado criterios ultrasonográficos endovaginales que se pueden usar para diferenciar los sacos normales de los anormales con un sólo examen con la especificidad y valor predictivo positivo cercanos al $100 \%$ (810). (Figuras III. 1a., III.1b).

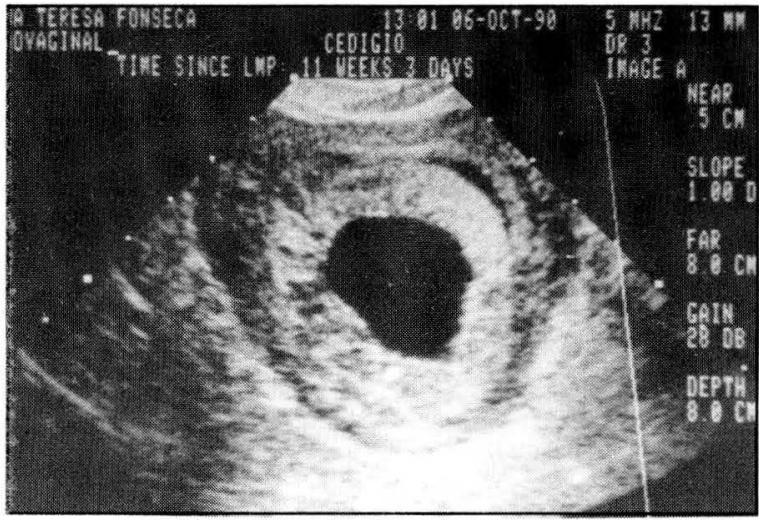

Figura III.1a

Saco gestacional de 11 semanas sin embrión ni vesícula vitelina con áreas de desprendimiento alrededor del trofoblasto.

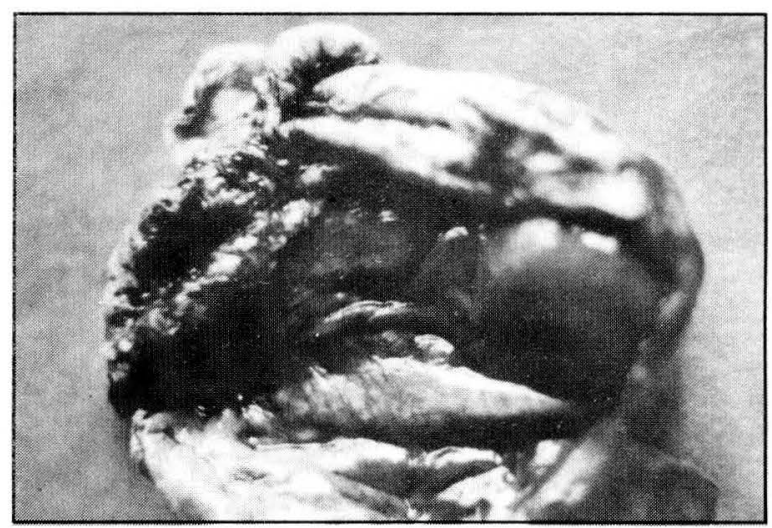

Figura III.1b

Espécimen macroscópico del mismo aborto anembrionado.

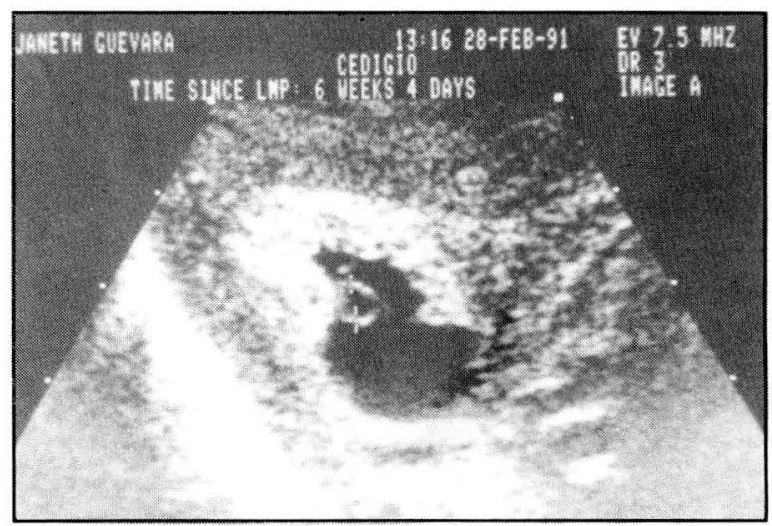

Figura III.2a

Embarazo de 6 semanas con saco gestacional de contornos irregulares y ecogenicidad variable, con vesícula vitelina de $3 \mathrm{~mm}$. 


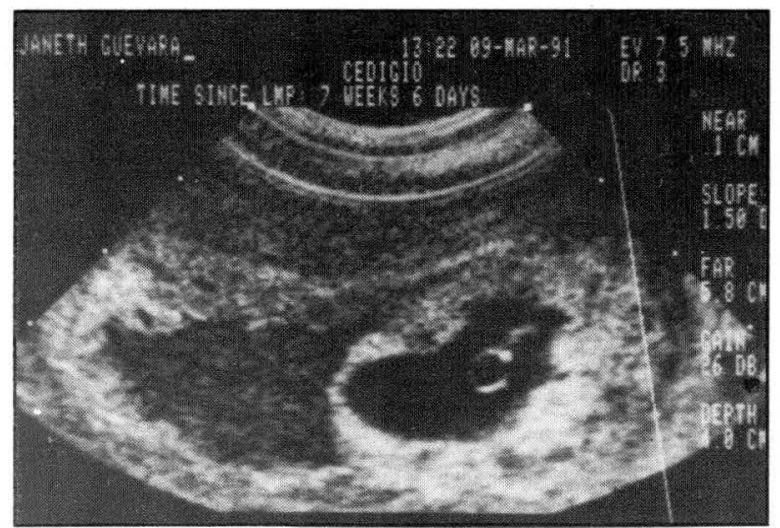

Figura III.2b

La misma paciente, con leve sangrado, una semana después; se observa una zona hipoecogénica a la izquierda del saco gestacional; imagen característica de un severo desprendimiento del saco. La paciente abortó 5 días después de esta ecografía.

Con la técnica de la US endovaginal el criterio de la presencia de un saco gestacional igual o mayor a $8-10 \mathrm{~mm}$ de diámetro que carece de vesícula vitelina o un saco gestacional igual o mayor a $16 \mathrm{~mm}$ de diámetro que carece de embrión, son de un pronóstico negativo para la viabilidad gestacional (2, 3, 6, 9, 10). (Figuras III.2a, III.2b y III.3a, III.3b, III.3c, III. $3 \mathrm{~d})$

\section{La visión embrionaria y sus estructuras ovulares}

A partir de la quinta semana puede observarse un embrión, el cual presenta un grosor entre $1-3 \mathrm{~mm}$ y se ve claramente diferenciado de la vesícula vitelina, tiempo en que aparece embriológicamente.

El embrión es ecorefrigente, de forma semilunar, junto a él se encuentra la vesícula vitelina que tiene forma de anillo que mide inicialmente $3 \mathrm{~mm}$ de diámetro, y crece un máximo de 5 a $6 \mathrm{~mm}$ en la 10a semana, tiempo en la cual está comprimida en un extremo del saco gestacional por el amnios (2, 3, 9-11).

Posteriormente, la vesícula comienza a desaparecer atrofiándose progresivamente e involucrándose en un pedículo de fijación, el cual se convertirá luego en el cordón umbilical. La imagen de la vesícula antes descrita debe estar presente en la US endovaginal normal $(8,12)$ (Figura III.4).

Es importante resaltar que la vesícula vitelina que hasta ahora no se le reconocía valor diferente al de datar una gestación cuando ésta no podía ser observada por la US abdominal, ha pasado a tener una mayor importancia ya que es una de las estructuras embrionarias más precoces. En ella se instaura la primera vascularización embrionaria, la onfalomesentérica, la cual será sustituida posteriormente, por consiguiente, al verla podemos garantizar que estamos ante una gestación de evolución normal (al menos inicialmente) y no ante un embarazo anembrionado $(3,8,12)$.

Por su parte, el embrión a partir de la 6 a semana adquiere un rápido desarrollo alcanzando $l o s ~ 10 \mathrm{~mm}$ en la 7a semana post-menstruación (5a gestacional), momento en el cual pueden comenzar apreciarse los esbozos de las extremidades, diferenciándose claramente el resto del cuerpo y del polo cefálico (8-11).
A partir de este momento puede seguirse el control detallado del crecimiento y desarrollo tanto del polo cefálico como del resto del embrión, puede medirse de forma más precoz y fidedigna la longitud cefalocaudal permitiendo así un fechamiento más preciso de la edad gestacional según los criterios ecográficos convencionales (Figuras III.4, III.5, III.6, III.7).
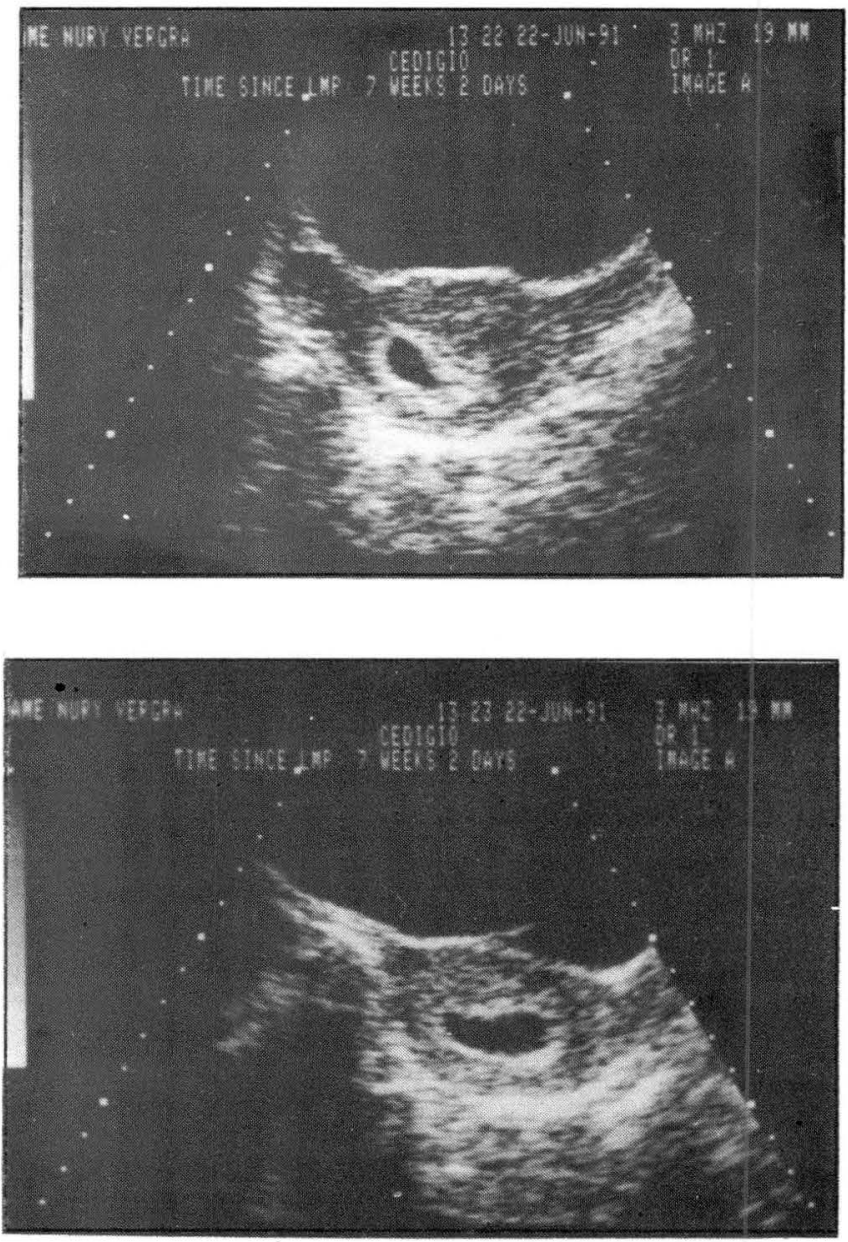

Figura: III.3a. y Fig. III.3b

Paciente con 7 semanas de edad gestacional x FUR, escaso manchado, sin modificaciones cervicales y con hipersensibilidad en cara anterior del útero. Se oberva por US abdominal saco gestacional sin embrión de forma y ecogenicidad dentro de parámetros normales.

A partir de la 7a semana la membrana amniótica es apreciable en casi el $100 \%$ de los casos y se observa como va ocupando todo el saco gestacional hasta llegar a fusionarse con el corion $(2,3,9,10)$.

\section{EI valor de la embriocardia}

Con la US endovaginal es posible identificar embriones desde $3 \mathrm{~mm}$ de diámetro longitudinal en adelante. Los textos clásicos de embriología indican que la actividad cardíaca en el embrión se inicia a los 21 días de edad embrionaria (36 días de edad menstrual o sea a comienzos de la $6 \mathrm{a}$. semana de edad gestacional por FUR) momento en que la longitud máxima 


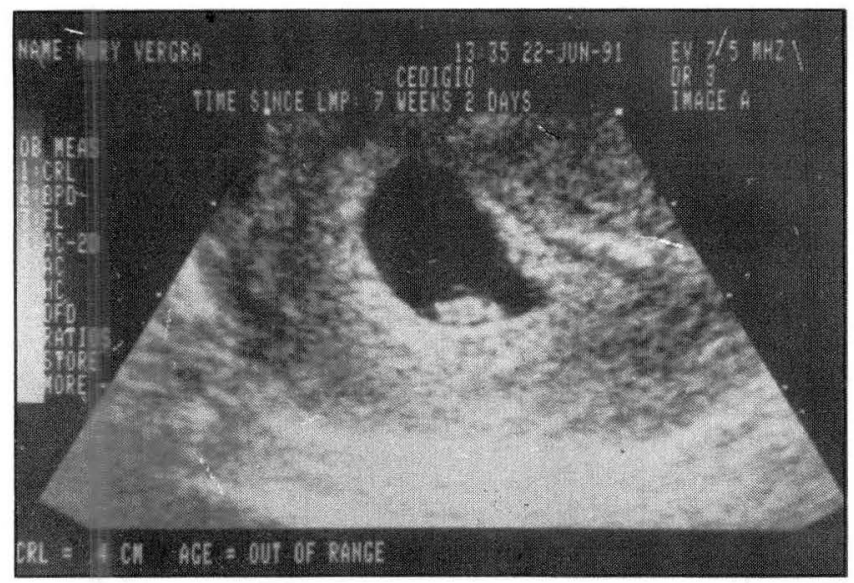

Figura: III.3c

El mismo día se observa en dicha paciente por "USE" un botón embrionario con embriocardia de un tamaño normal al rango normal

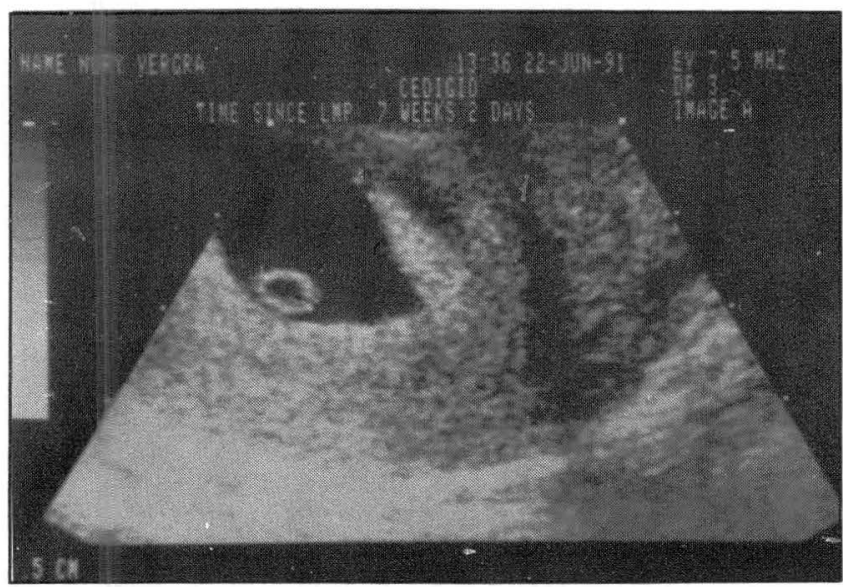

Figura. III.3d

En el mismo examen se observa vesícula viteliana de tamaño y ecogenicidad normal, esta fue desapareciendo en estudios ulteriores y tres semanas después del presente estudio la paciente abortó.

del embrión se encuentra entre 2 y $3.0 \mathrm{~mm}$, siendo posible demostrar la actividad cardíaca en dicha semana.

Lo único conclusivo sobre estos aspectos, es que en el momento de la visualización endosonográfica de la embriocardia se descarta (como es obvio) la muerte embrionaria y permite deducir una buena evolución de la gestación en el primer trimestre del embarazo en la mayoría de los casos (8-10).

\section{Primer trimestre patológico: Hallazgos ultrasonográficos endovaginales y su correlación con niveles séricos de HCG}

La US endovaginal es un instrumento importante en el diagnóstico de patologías del primer trimestre, como: aborto, embarazo ectópico y la degeneración hidrópica del trofoblasto.

La US endovaginal tiene la capacidad de visualizar el saco gestacional desde etapas muy tempranas, lo que lo hace un buen método para el diagnóstico de embarazos normales y anormales.

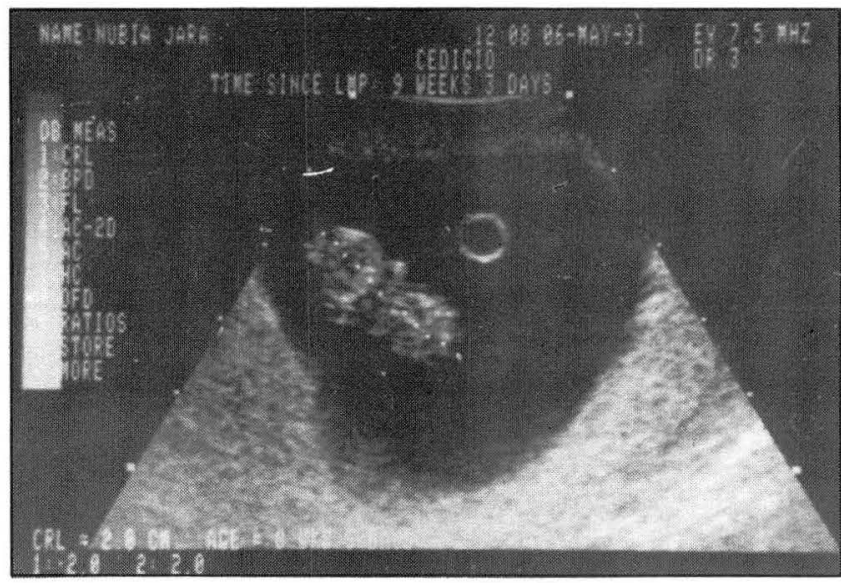

Figura III.4

Correcta medición de la longitud cráneo-caudal por "USE" a un embrión de 9 semanas postmenstruales con vesícula vitelina y desarrollo embrionario normal.

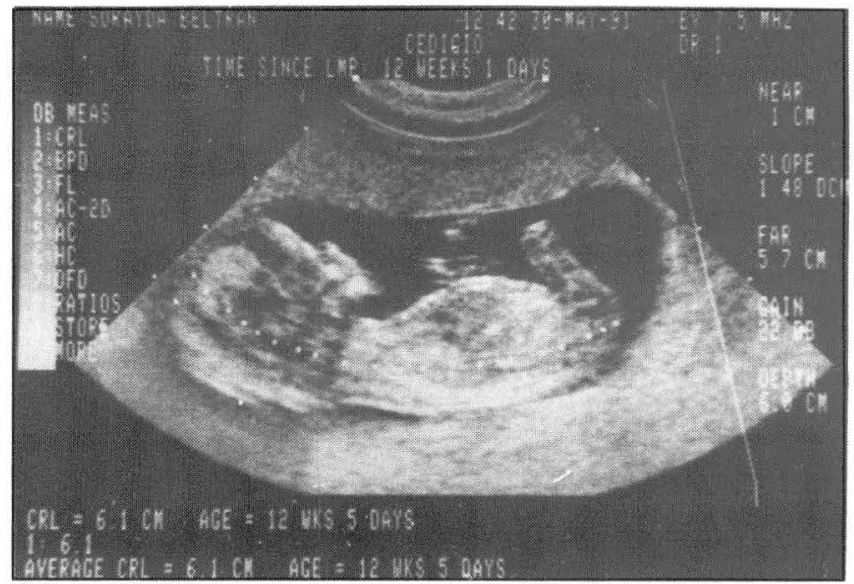

Figura III.5

Embrión normal de 12 semanas con una correcta medida de la LCC. se aprecia claramente el perfil de la cara, abdomen, extremidades y cordón umbilical.

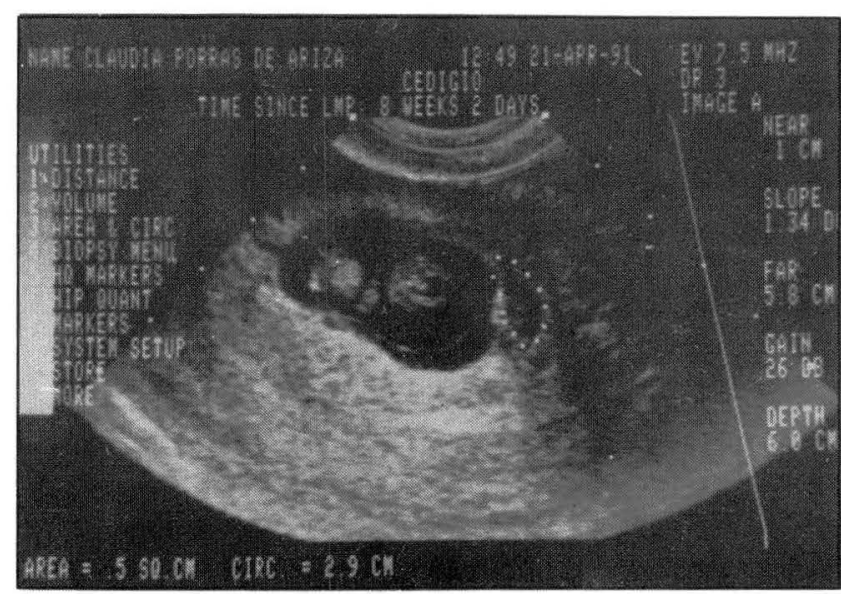

Figura III.6

Embarazo de 8 semanas postmenstruales por "USE" donde se aprecia un desprendimiento: de $2.9 \mathrm{~cm}$ de área completamente asintomática (línea punteada) 


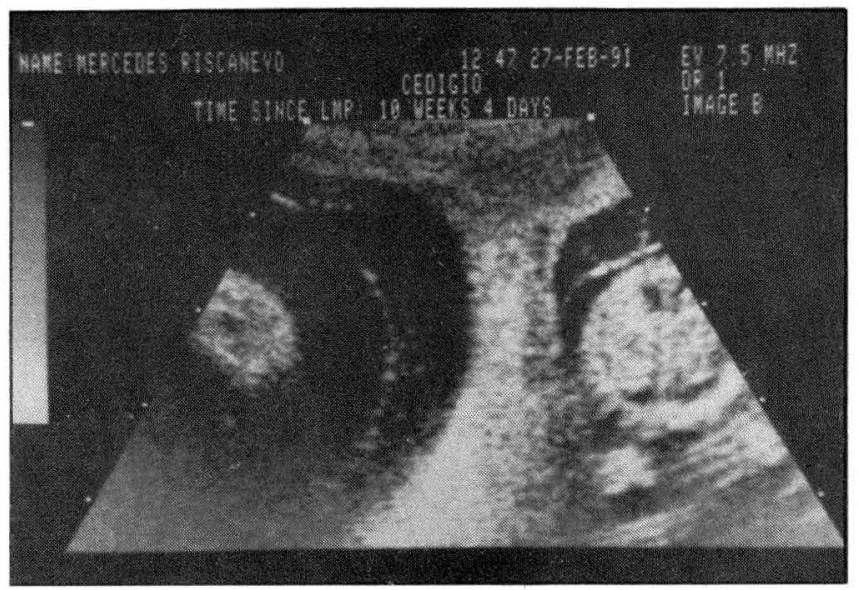

Figura III.7

Embarazo gemelar por "USE" de 10 semanas postmenstruales, se observa zona "T", ammios sin fusionarse a la derecha y plexos coroides normales a la izquierda.

Estudios previos indican que la correlación de los hallazgos seriados ultrasonográficos con la determinación sérica simultánea de BHCG es un método útil para evaluar las complicaciones de un embarazo inicial, particularmente cuando no se ve el saco gestacional o éste es muy pequeño y no se visualiza el embrión o no puede observarse la embriocardia (1).

Investigaciones iniciales establecieron a este respecto una "Zona Discriminatoria" de niveles de BHCG para el diagnóstico del embarazo normal, consistente en la correlación de niveles séricos iguales o superiores a $6.500 \mathrm{mUI} / \mathrm{ml}$. (Primer Standard Internacional) con la visualización ecográfica del saco gestacional (2-4).

Posteriormente, con el advenimiento de nuevos equipos de ultrasonografía abdominal de mayor resolución, se observó que se podía reducir la "Zona Discriminatoria” a 3.600 $\mathrm{mUI} / \mathrm{ml}$. (Primer Standard Internacional) sin menoscabo de su fidelidad diagnóstica (2-4).

Ahora, con el avance de la US endovaginal se ha propuesto una “Zona Discriminatoria" de $1.800 \mathrm{mUI} / \mathrm{ml}$. ( ler standard) cuando se visualiza el embrión (longitud cráneo-caudal de 2-3 mm. en adelante). Por otra parte, cuando sólo se ve el saco gestacional los valores deben realizarse seriados (dos tomas con 24-48 horas de intervalo) siendo en estos casos el rango discriminatorio aceptado para viabilidad gestacional de 750 a $1.500 \mathrm{mUI} / \mathrm{ml}$. y su mayor valor diagnóstico se expresa en la tendencia ascendente o descendente de estos niveles séricos de BHCG. Dichos niveles van correlacionados al mismo tiempo con observaciones ultrasonográficas endovaginales (2-4). (Figuras II.2a, II.2b, II.2c).

Niveles inferiores a estas cifras o la tendencia progresiva a su disminución se relaciona en un alto porcentaje con la no viabilidad de la gestación, lo cual es corroborado con las imágenes endosonográficas que se realizan concomitantemente con dichos valores. (Figuras IV.1a, IV.1b, IV.1c, y IV.2).

Los anteriores parámetros son perfectamente válidos para el embarazo ectópico, sobre todo cuando no se observa saco gestacional en la cavidad endouterina. Esta correlación entre niveles séricos de BHCG y US endovaginal son claves para el

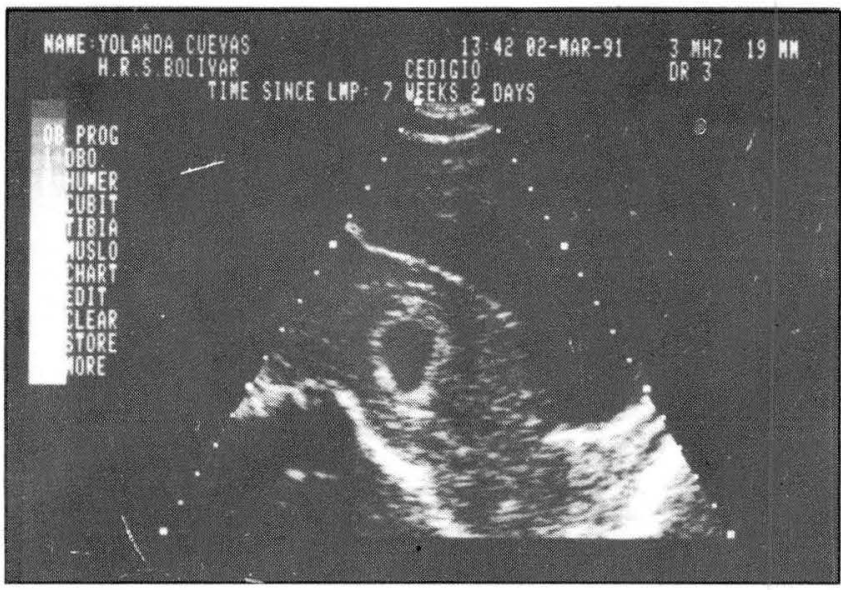

Figura IV.la

Paciente con 7 semanas de amenorrea, $2.080 \mathrm{mUI} / \mathrm{ml}$, con US abdominal mostrando saco gestacional sin embrión.

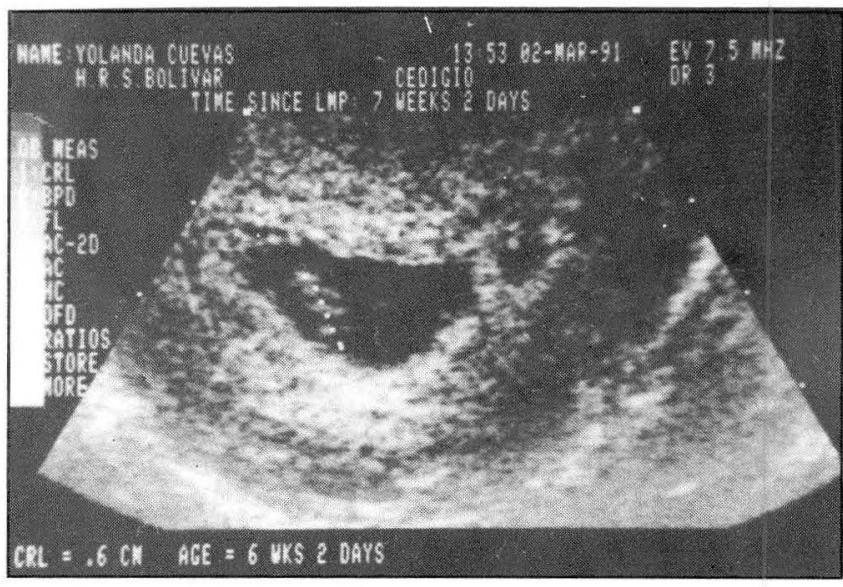

Figura IV.1b

El mismo día por "USE" se observa embrión de $0.6 \mathrm{~cm}$. para una edad gestacional de 6 semanas y se observa claramente la embriocardia.

diagnóstico precoz de embarazo tubárico no roto, mejorando así el futuro obstétrico de la paciente (6).

Después de lo anterior queda muy factible concluir que la estrecha correlación entre el tamaño del saco gestacional y los niveles séricos de BHCG existe debido a que en definitiva ambos son producto de la actividad trofoblástica. Por lo tanto, es muy razonable esperar que con diferentes tipos de equipos ultrasonográficos abdominales y endovaginales con diferentes niveles de resolución de imagen se tengan diferentes umbrales o zonas discriminatorias de $\mathbf{B H C G}$, por encima de los cuales los sacos gestacionales serán suficientemente bien visualizados (3-5).

La correlación de los niveles de BHCG con la exploración ultrasonográfica como se expuso anteriormente no es la única forma diagnóstica de la problemática del primer trimestre, indiscutiblemente la US endovaginal ofrece por sí sola una extensa gama de imágenes que sin duda alguna son de gran valor diagnóstico.

La US endovaginal tiene la capacidad de detectar un embarazo intrauterino o excluirlo mínimo una semana antes que la US transabdominal, de la misma manera puede obser- 


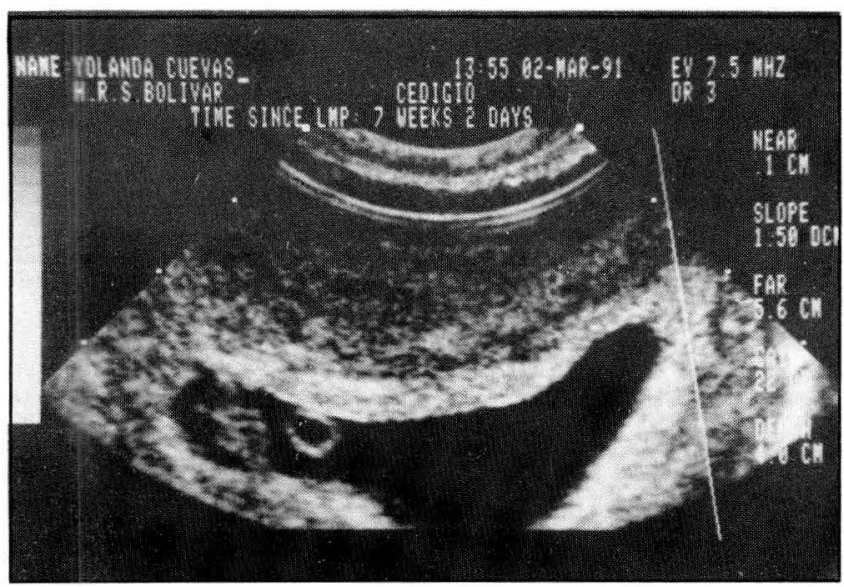

Figura IV. 1c

El mismo día por "USE" se observa la vesícula vitelina; la BHCG de 48 horas más tarde fue de $2.930 \mathrm{mUI} / \mathrm{ml}$, el embarazo progresó normalmente.

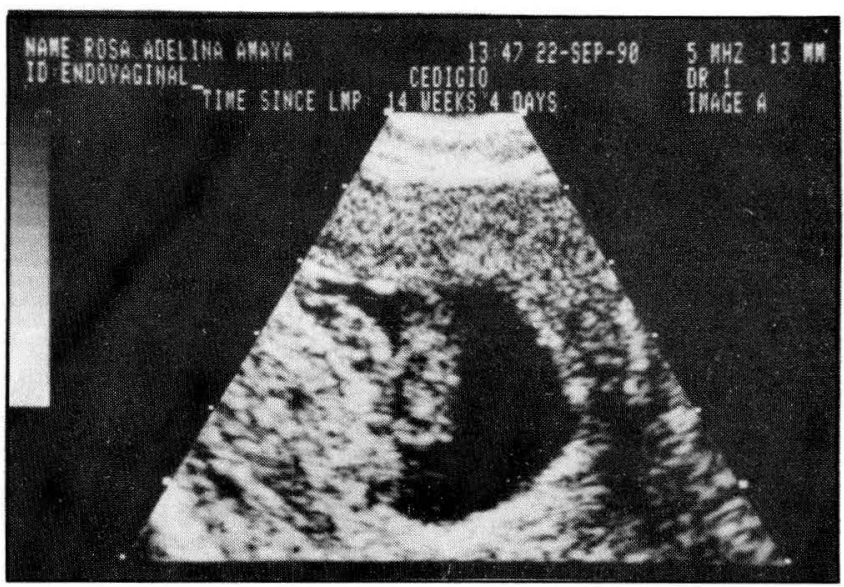

Figura IV.2

Embarazo de 14 semanas con $B H C G$ de $1.200 \mathrm{mUI} / \mathrm{ml}$, embrión de ecogenicidad y morfología difusa, sin embriocardia, saco gestacional irregular; IDx: Aborto retenido.

Hay que tener cuidado en no confundir el diagnóstico de un embarazo ectópico cornual con un embarazo intrauterino en el lado más desarrollado de un útero bicorne ya que sus imágenes son muy similares, aunque con la experiencia del examinador en ambas técnicas ultrasonográficas (abdominal y endovaginal) y con una historia clínica completa se llegará sin duda a un diagnóstico acertado (11-13, 27).

El embarazo ectópico cervical aparece como un saco gestacional implantado anormalmente en la parte más baja del útero, sin embargo esta imagen puede parecerse a un saco gestacional no viable en proceso de aborto $(11-13,27)$.

Los embarazos abdominales son en la mayoría de las veces el resultado de un embarazo tubárico abortado a cavidad abdominal con la subsecuente fijación de este saco en la cavidad peritoneal preferentemente en el momento, mesenterio o fondo de saco de Douglas. Este tipo de embarazo es muy difícil de reconocer, sin embargo los signos ultrasonográficos diagnóstico radican en tratar de observar el útero como una estructura independiente del saco gestacional y eventualmente de una placenta ya existente (11-13).

Este útero debe observarse con paredes endometriales gruesas e hiperecogénicas y con endometrio desidualizado muy diferente a la imagen miometrial de un útero con embarazo intrauterino. Además, si se complementa esta observación con la visión ultrasonográfica transabdominal en etapas gestacionales más avanzadas (de la semana 12 a 14 en adelante) se podrá observar una implantación fetal anormal, oligohidramnios y líquido peritoneal abundante.

\section{Tratamiento no quirúrgico del embarazo ectópico tubárico no roto}

Por ser la US endovaginal un método de visualización anexial bastante expedito, algunos investigadores están proponiendo un tratamiento no quirúrgico para el embarazo ectópico no roto consistente en la aspiración de líquido del saco gestacional y la inyección en el mismo de $50 \mathrm{mg}$ de methotrexate bajo visión endovaginal y con anestesia local obteniendo aparentemente buenos resultados a corto plazo y 


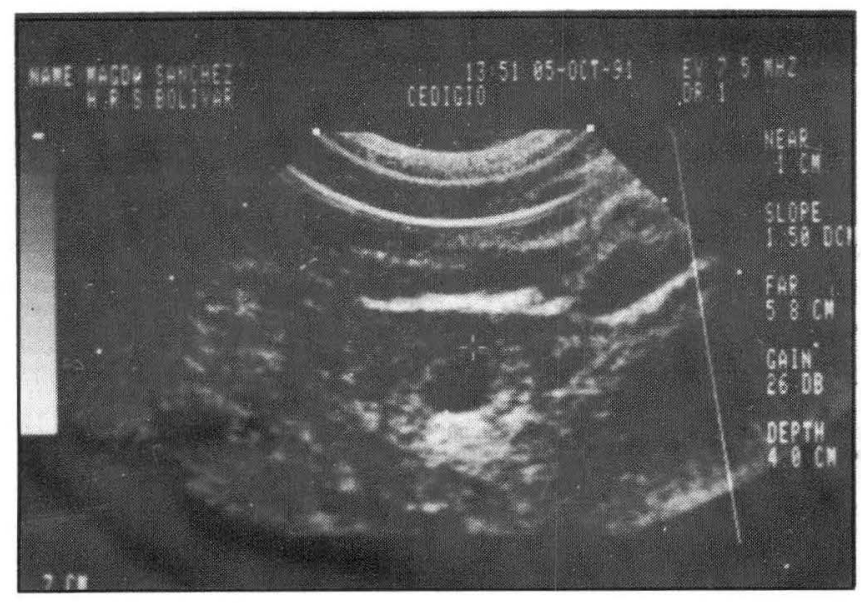

Figura IV.3a

Se observa saco gestacional en anexo derecho con una luz de $0.7 \mathrm{~cm}$, rodeada de un doble anillo hiperecogénico. La paciente presentó en ese momento 2 semanas de amenorrea y una B HCG de $800 \mathrm{mUL} / \mathrm{ml}$, hasta este momento el cuadro clínico es asintomático.

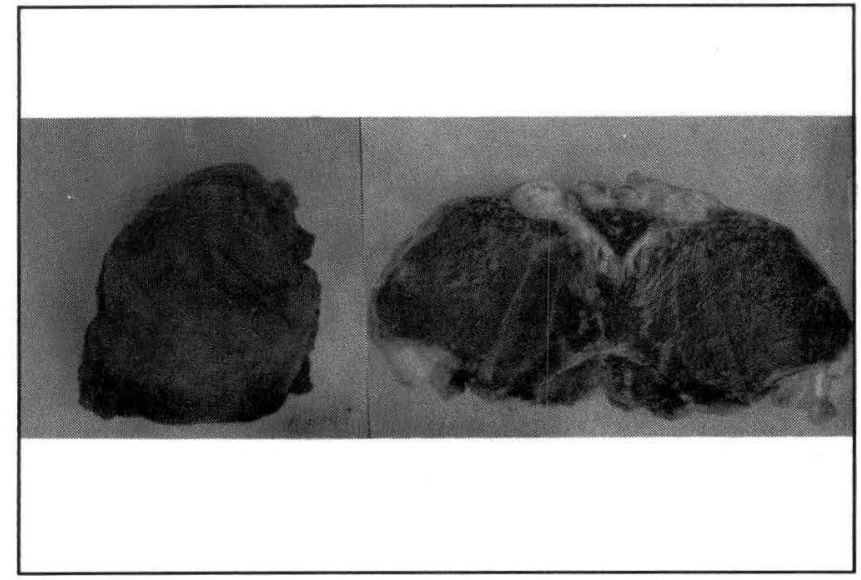

Figuras IV.3c y IV.3d

Por estar asintomática, la paciente no aceptó las recomendaciones terapéuticas, asistiendo al hospital 3 días después con dolor agudo y sangrado, fue operada obteniéndose un embarazo tubárico no roto que comprometía severamente el tejido tubárico; la extracción se realizó por salpingectomía parcial de tercio medio. Un acercamiento de esta pieza Qx se ilustra en estas 2 figuras.

con una morbilidad de procedimiento reportada como pequeก̃a (14).

A este respecto hacen falta estudios para definir resultados a largo plazo sobre la funcionalidad de la trompa y sobre la futura fertilidad femenina en general $(14,15)$.

Este procedimiento ha presentado como inconveniente la subsecuente elevación sérica de BHCG posterior a la administración de methotrexate, hecho que intranquiliza al médico, ya que no se sabe si esta elevación es debida a la acción del methotrexate sobre el trofoblasto o por un aumento inherente al crecimiento trofoblástico del embarazo ectópico (22).

Por esta razón se está proponiendo la luteolisis asistida, consistente en aplicar al cuerpo lúteo a través de una punción dirigida por US endovaginal sustancias altamente luteolíticas suprimiendo así el soporte hormonal del embarazo ectópico,

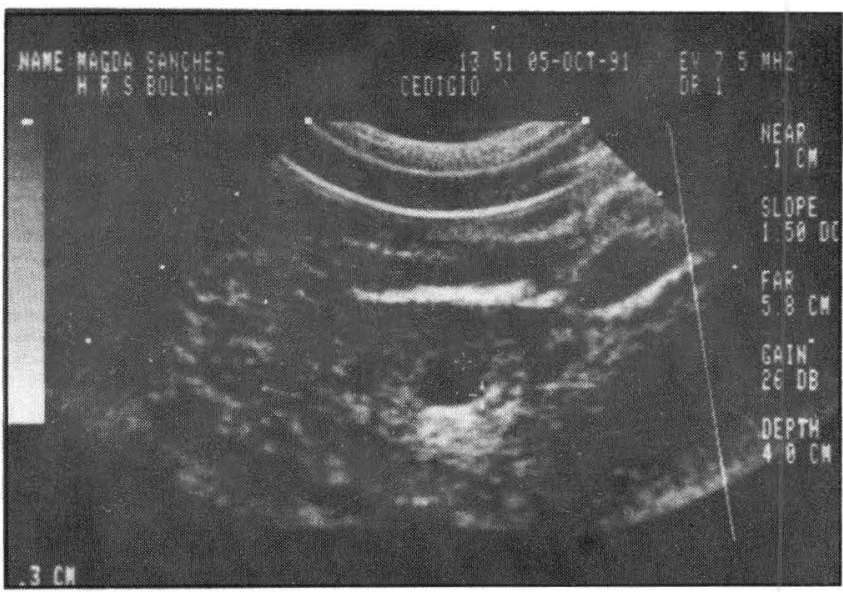

Figura IV.3b

Otra toma de la misma ecografía donde se aprecia el saco gestacional ectópico con la vesícula vitelina que mide $0.3 \mathrm{~cm}$; este es un signo ecográfico de certeza diagnóstica en el embarazo ectópico tubárico.

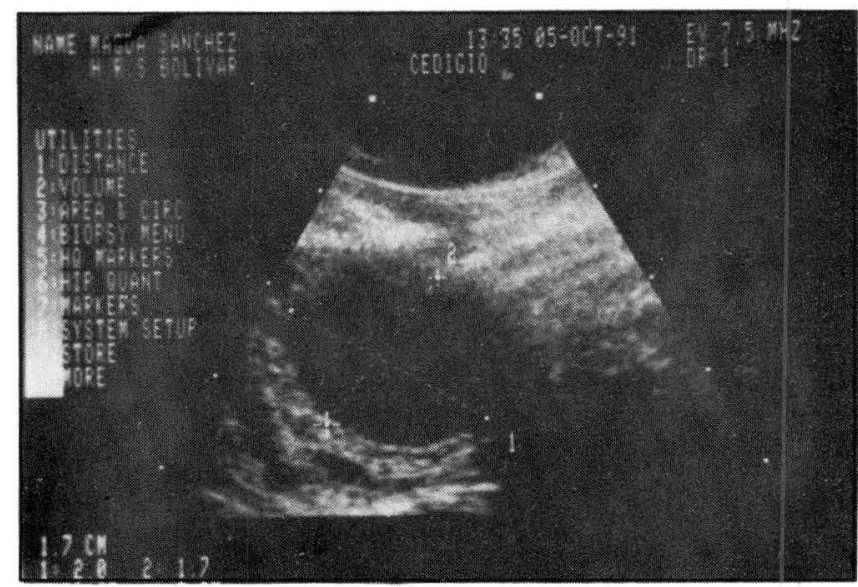

Figura IV.3e

Imagen del cuerpo lúteo de esta paciente, mide $2.0 \mathrm{~cm} \times 1.7 \mathrm{~cm}$, es una imagen característica de un cuerpo lúteo gestacional temprano, por US endovaginal.

entrando éste por consiguiente en una regresión y reabsorción del mismo (21) (Figura I.1).

Para el anterior efecto se proponen por diferentes investigadores como sustancias luteolíticas: las prostaglandinas (16), la prolactina $(17,18)$, los estrógenos conjugados (19) y el RU $486(19,20)$.

A este respecto los trabajos de investigación que se realicen y al tiempo de seguimiento tendrán la última palabra sobre esta nueva proposición terapéutica.

\section{Endosonografía en la enfermedad trofoblástica}

Esimportante recordarel papel que juega la US endovaginal en el diagnóstico de la enfermedad trofoblástica gestacional.

Su principal elemento en la detección temprana de la degeneración hidrópica de las vellosidades es la observación de un patrón vesicular descrito como Imagen en Panal de Abeja. 
Las características ecográficas de una mola son más evidentes en la medida en que ésta avanza en edad gestacional. Estas características se presentan en un principio muy homogéneas entre la 8a y 12a semana tiempo en que la vellosidad corial mide aproximadamente $2 \mathrm{~mm}$.

Por encima de la anterior edad gestacional, el patrón imagenológico vesicular se va haciendo más evidente y delimitado entre las zonas hipo e hiperecogénicas observándose el cuadro típicamente claro entre la 16a y la 20a semana, momento en que la vellosidad trofoblástica mide de 8 a $10 \mathrm{~mm}$ (mola madura) (23-25).

En esta entidad es posible ver con alguna frecuencia múltiples imágenes ováricas compatibles con cuerpos lúteos, esto se denomina hiperactividad lútea del ovario y consiste en una luteinización masiva de varios folículos ováricos como resultado de una hipersensibilidad de estos a los altos niveles circulantes de BHCG. Este patrón entra en franca resolución una vez solucionada la enfermedad trofoblástica.

\section{Diagnóstico diferencial de enfermedad trofoblástica por US endovaginal.}

La visión de las vesículas se presenta a partir de la 5a a 6 a semana en adelante, tiempo en que aparecen embriológicamente. La US endovaginal es fundamental en la diferenciación diagnóstica antes mencionada en la medida que permite:

A. Observar el inicio de la transformación molar.

B. Ver restos embrionarios, amnios y vesículas de forma temprana (antes de la 10a semana).

C. Apreciar las características de los sacos gestacionales con molas embrionadas y no embrionadas como son:

Su mala delimitación interna, el estar rodeados de un ribete de trofoblasto muy denso, grueso y ecorefrigente.

La degeneración hidrópica de la placenta asociada con abortos incompletos es la condición más común que puede simular la apariencia de un embarazo molar (11, 23-25). (Figuras IV.4a, IV.4b).

Las áreas hidrópicas pueden ser focales o difusas y aparecer como espacios anecoicos dentro de la placenta. Por lo tanto, un feto podría o no estar presente concomitantemente con una degeneración hidrópica de la placenta. No obstante, los niveles séricos de BHCG están generalmente más bajos en la degeneración hidrópica que en las molas completas o parciales; probablemente por el número reducidode trofoblasto funcionante en estos casos. Los cambios hidrópicos de la placenta pueden estar asociados con triploidías o poliploidías (11, 23-25) (Figuras IV.5a, IV.5b).

Otras imágenes que eventualmente pueden presentar patrones endosonográficos que confunden al observador como son la presencia de miomas submucosos con degeneración hialina y/o mixomatosa con múltiples zonas hemorrágicas y abundantemente tabicadas. Sin embargo, esta duda ultrasonográfica es muy sencilla de dirimir, ya que esta cantidad no cursa con niveles elevados de BHCG (26).

Finalmente, podemos concluir que pacientes con productos de la concepción retenidos y hemorragia, pueden simular una apariencia endosonográfica de embarazo molar. Diferenciar estas dos situaciones exclusivamente por endosonografía no es tarea fácil ya que en muchas ocasiones el patrón vesicular es muy parecido (28); los títulos seriados de BHCG son de mucha utilidad en estos casos.

\section{El papel de la US endovaginal en el diagnóstico embrionario de anomalías congénitas}

El diagnóstico prenatal de anomalías congénitas ha avanzado mucho en la práctica obstétrica moderna. Con el advenimiento de la US endovaginal se obtiene un examen más detallado y temprano del embrión durante el primer trimestre. Esta mejor visualización conlleva a un mayor entendimiento del desarrollo embriológico normal y a la detección de anomalías congénitas en las primeras 12 semanas de edad gestacional.

El diagnóstico temprano reduce la morbilidad y los costos asociados a un aborto espontáneo o inducido en el segundo o tercer trimestre (en países donde su legislación lo permite), así como la ansiedad generada por la espera de una prueba diagnóstica tardía.

Se ha descrito en gran detalle la apariencia ultrasonográfica de la embriología normal, constituyéndose éste conocimiento en una excelente base para la detección de las anomalías embrionarias.

A continuación se presentará de una forma breve y concisa las principales anomalías embrionarias por regiones anatómicas:

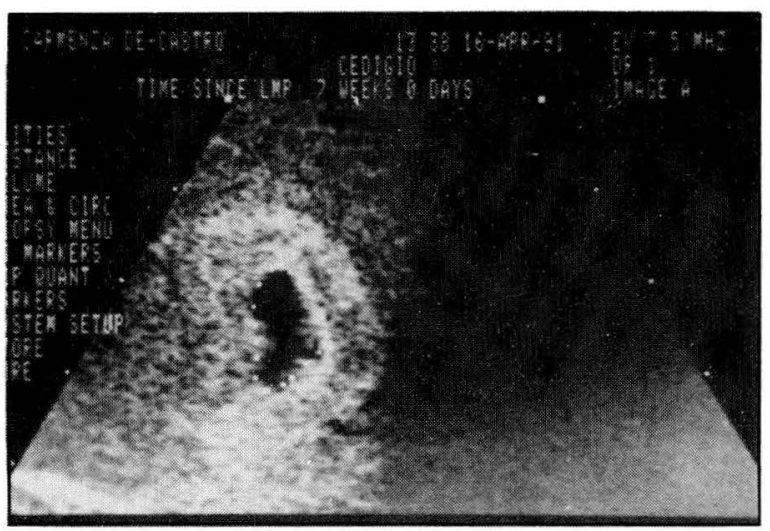

Figura IV.4a

Paciente de 40 años con 7 semanas de amenorrea, saco irregular, engrosado, con una imagen hacia su luz en forma de flecos, la cual es de mal pronóstico.

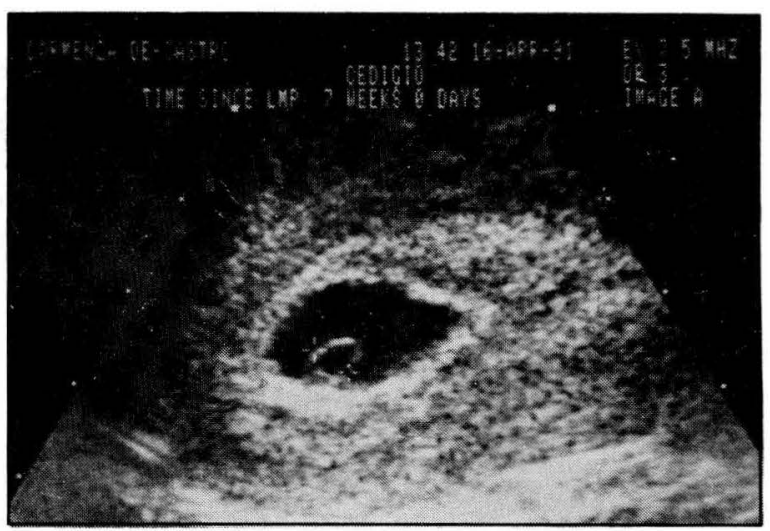

Figura IV.4b

La vesícula vitelina pequeña para su edad gestacional; la paciente abortó una semana después, la patología reportó un aborto con degeneración hidrópica del trofoblasto. 


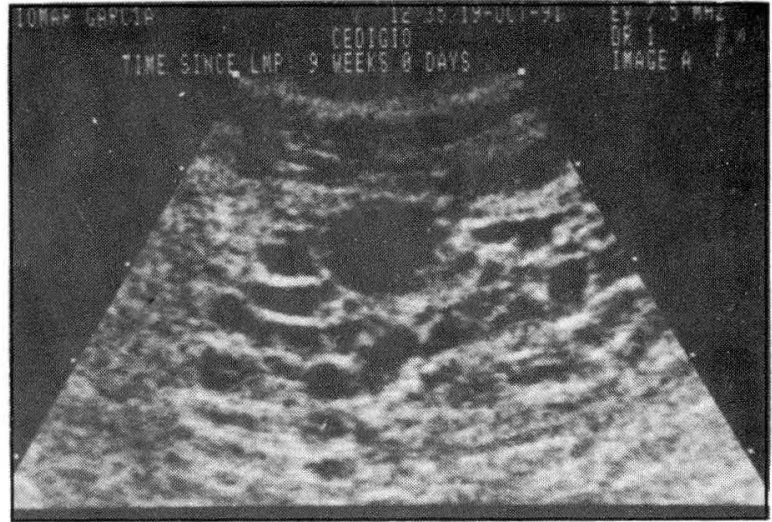

Figura IV.5a

Imagen endosonográfica de una mola de 9 semanas, caracterizada por múltiples espacios anecoicos e irregulares en forma de panal de abeja.

A.- Cabeza y cuello: La anatomía intracraneal normal aparece inicialmente con un sólo ventrículo a la altura de las 8 semanas. Los plexos coroides prominentes sólo se visualizan hasta la novena semana, la calvaria o calota y el cerebelo no son evidentes sino hasta la décima semana. Se puede ver una pequeña cantidad de corteza en la periferia al término de la 12a semana (Gráficas V.1 y V.2) y (Figuras V1, V2, V3, V4, V.5).

El diagnóstico antenatal de hidrocefalia sin craneomegalia no es posible debido a la proporción relativamente grande de los ventrículos laterales con respecto a la calota. Por las observaciones anteriores de la neuroanatomía normal se puede deducirque la anencefalia, exoencefalia, el encefalocele y la acránea no se pueden diagnosticar sino después de la 10a semana cuando la calota está calcificada (1-4).

La exoencefalia se diagnostica por la presencia de una masa irregular que presenta tejido neural y vascular desorganizado con ausencia de calota. La anencefalia, que se consideró como un avance de la exoencefalia por abrasión mecánica se puede observar en una gestación a la altura de la semana 12a a 14a. El diagnóstico de encefalocele debe considerarse si se ve un cráneo calcificado con protrucción de tejido neural (1-4).

B.- Cara: La mandíbula y el maxilar se visualizan a la 10a semana, tres semanas después del tiempo en que ocurre la fusión completa de las estructuras de la línea media. No se han reportado casos diagnósticos de falla de hendiduras en la línea media (paladar hendido) en el primer trimestre del embarazo, aunque en un futuro podría ser posible este diagnóstico. (Figura V.6)

El pabellón auricular se ve a las 8 semanas, por consiguiente la implantación baja del mismo se puede detectar, estos hallazgos están asociados con múltiples anomalías congénitas entre ellas la trisomía 13 (1-4).

C.- Médula espinal: El cierre del tubo neural y la calcificación de la lámina espinal no ocurren sino hasta la 7a10a semana de gestación respectivamente, para este tiempoes posible diagnosticar algunas alteraciones del tubo neural (14) (Figuras V.7, V.8, V.9).

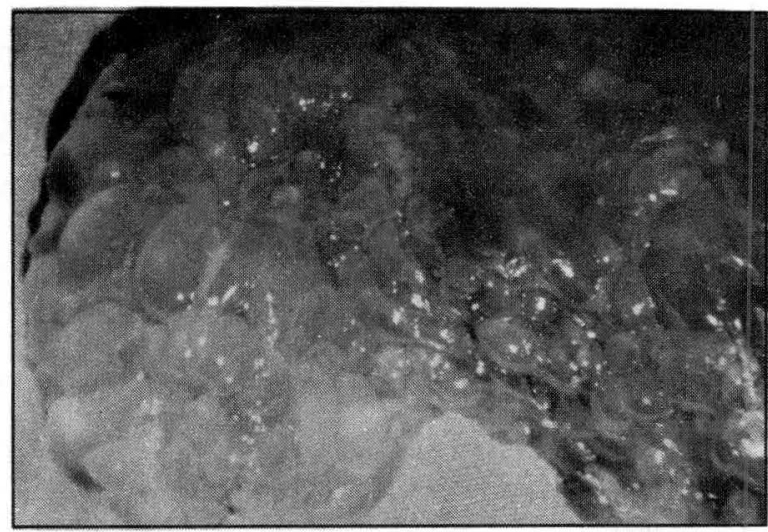

Figura IV.5b

Imagen fotográfica ampliada del espécimen macroscópico de dicha mola.

D.- Pared ventral: La pared ventral del embrión se evidencia hasta la 6a semana. La hernia fisiológica del intestino en el cordón umbilical proximal se puede demostrar entre las semanas 9 y 12 como un engrosamiento de la inserción del cordón. Si la hernia se nota después de la 12a semana se debe sospechar un onfalocele o una posible gastroquisis $(5,10)$ (Figura V.6).

E. Extremidades y dedos: Las extremidades en formación se pueden apreciar a la altura de la semana 7a, los huesos largos aparentemente se calcifican a la 10a semana, los dedos se pueden identificar a partir de la 11-12a semana, tiempo en el cual se pueden diagnosticar polidactilias, sindactilias, mesomelias, focomelias y otras alteraciones morfológicas de las extremidades (6). (Figuras V.10, V.11).

F. Corazón: Se puede obtener una imagen de las 4 cámaras cardíacas a partir de la 11 a a 12a semana imagen que descarta de plano el $95 \%$ de las anomalías anatómicas cardíacas. La transposición de los grandes vasos, la estenosis pulmonar y las valvulopatías auriculoventriculares no son fáciles de apreciar, según la literatura mundial (1) se han

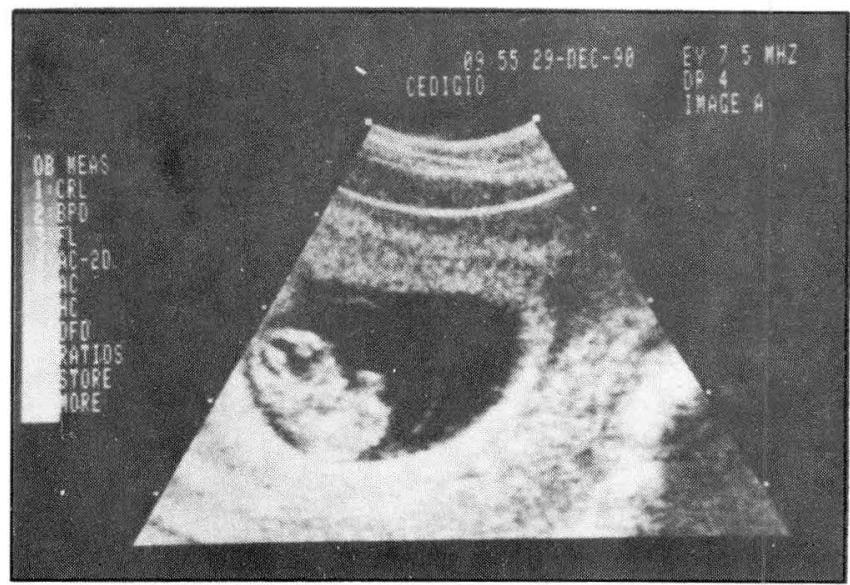

Figura V.1

Embrión normal de 8 semanas con su ventrículo único en formación. 


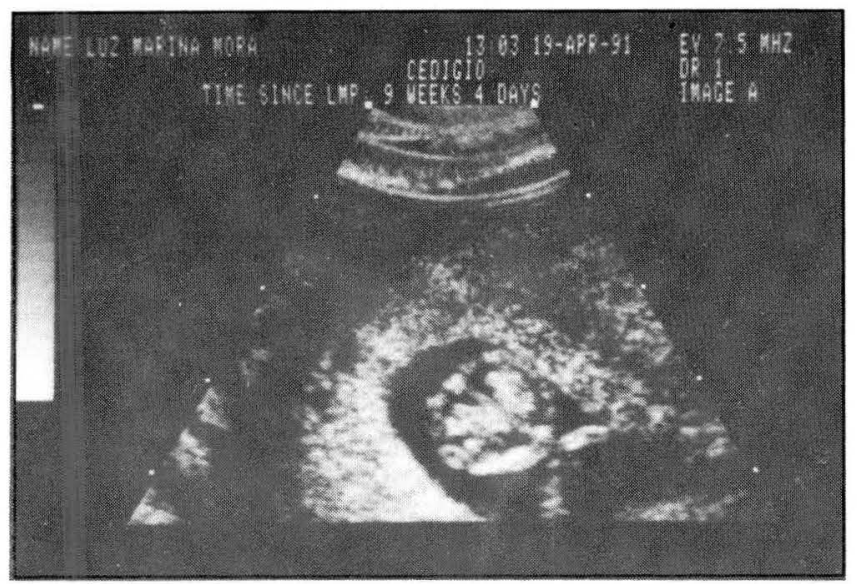

Figura V.2

Embrión de 9 semanas con un corte occipital semicoronal donde se aprecian claramente los plexos coroideos.

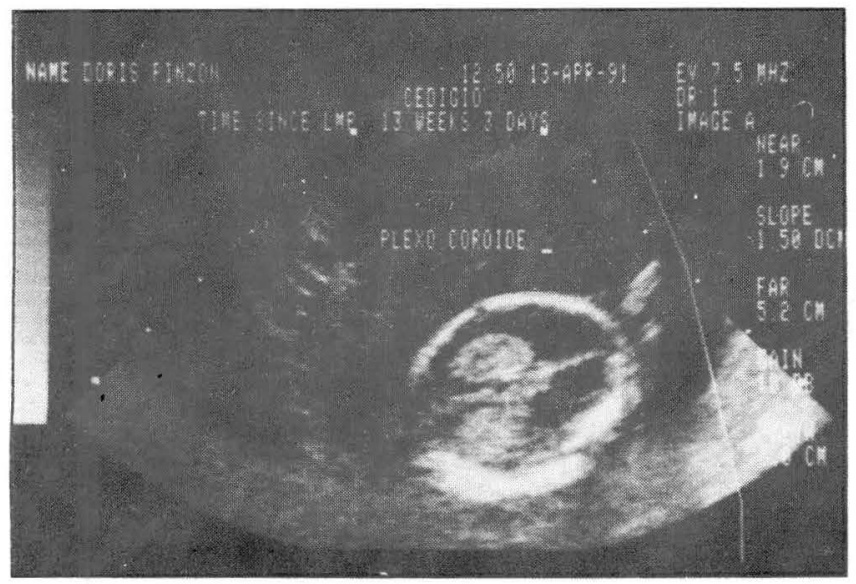

Figura V.4

Corte axial de la cabeza de un embrión de 13 semanas, se observan el cabum septum pelucidum, los plexos coroides, el pedúnculo cerebral, los ventrículos laterales, y parte del espacio subaracnoideo y de la prensa de

herófilo.

logrado imágenes diagnósticas a partir de la 11a a 13a semana siendo estas no conclusivas; sólo con ecografías transabdominales seriadas se han podido lograr imágenes diagnósticas a la altura de la semana 22 a $24(1,6)$.

Gráfica V.1

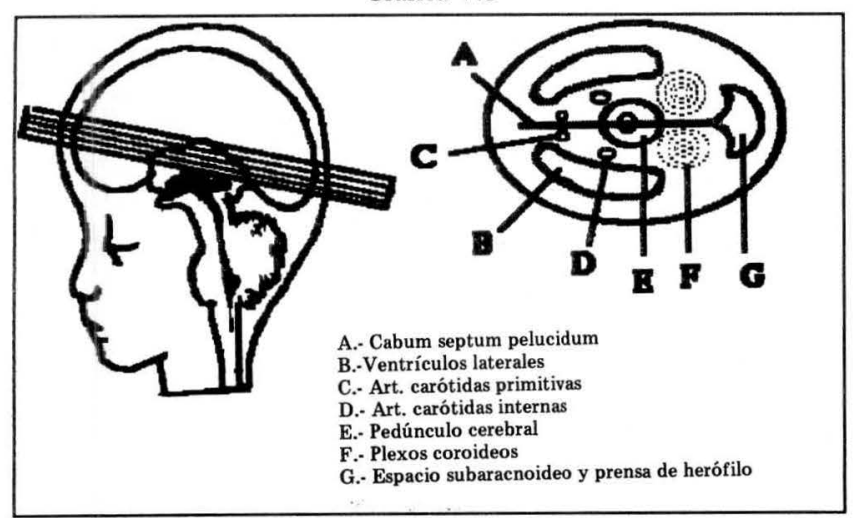

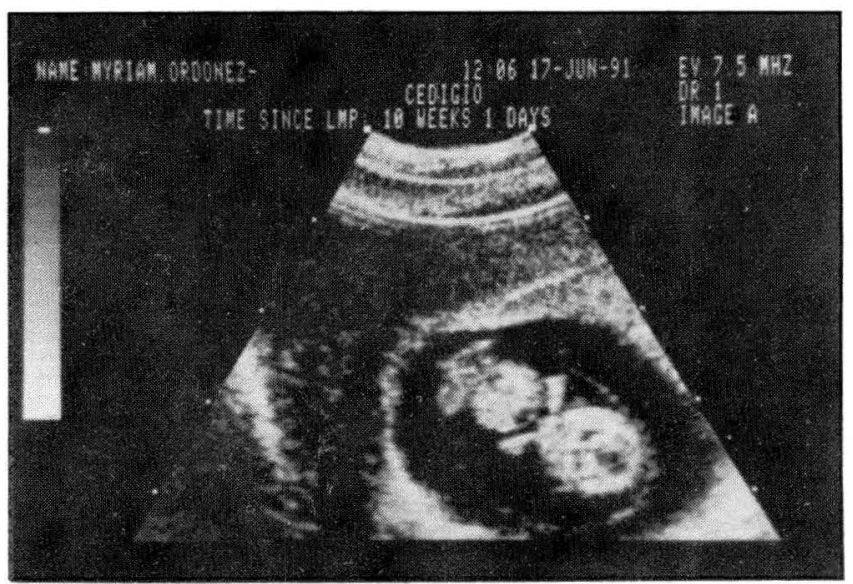

Figura V.3

Embrión normal de 10 semanas, se observa el amnios, la calota, el cuerpo $\mathrm{v}$ las extremidades.

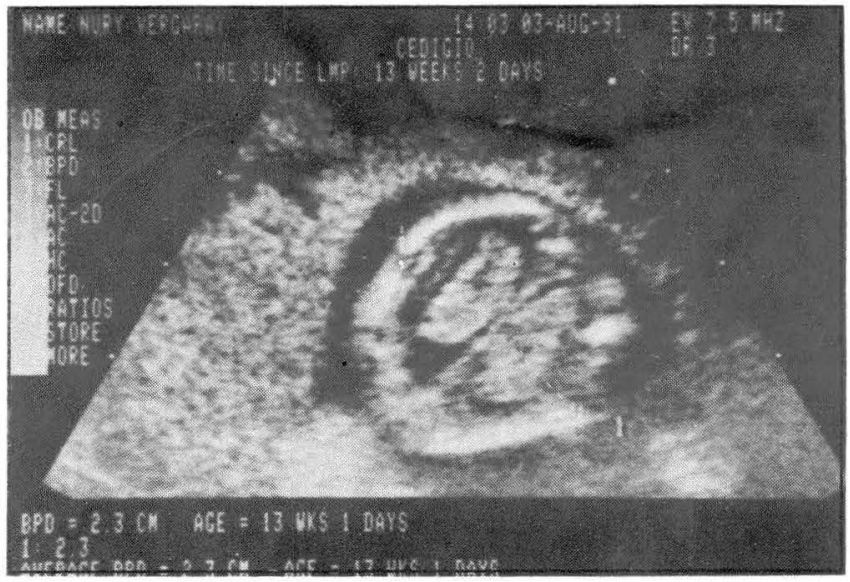

Figura V.5

Corte semicoronal de los plexos coroideos, se observan ocupando casi en su totalidad la zona occipital de la cabeza fetal (13a semana de gestación).

En cuanto a la ecocardiografía fetal por transductor endovaginal no se tiene claro (por ahora) la sensibilidad y especificidad de dicho método en el examen y diagnóstico

Gráfica V.2

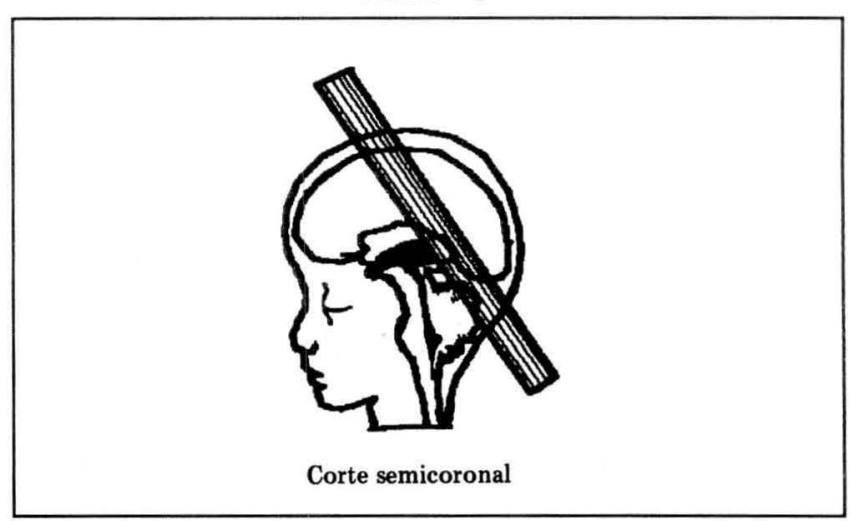


temprano de las anomalías cardíacas, así como sus verdaderas indicaciones (1-4).

G.-Genito urinario: Se puede obtener una visión renal y vesical adecuada desde la 10a-11a semana. A partire de la 11a semana el parénquima se observa hiperecoico y por el contrariola vejiga se identifica como una imagen quística e hipoecoica.

En literatura describen la capacidad de la US endovaginal para diagnosticar uropatías obstructivas en el primer trimestre, entre ellas se incluyen las megavejigas y la hidronefrosis. La dilatación de la vejiga se diagnóstica por la demostración de una estreuctura quística sonoluscente grande en la pelvis fetal (1).

La detección temprana de una agenesia renal es posible a partir de la 12a semana por la no visualización de riñón y vejiga. Al igual que la diferenciación anatómica de los genitales fetales, ya que ésta no es completa hasta la 12a semana cuando el falo masculino es identificable. (Figura V.12).

En esto de la determinación del sexo se pueden lograr imágenes acertadas a muy temprana edad, en un gran número de veces esto no es fácil por más experiencia que tenga el ecografista, ya que necesita una cierta complicidad fetal en su

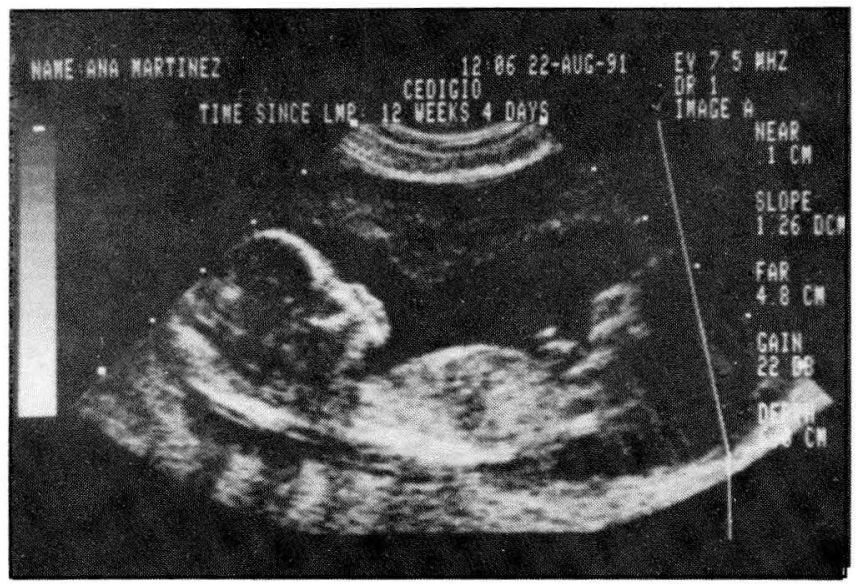

Figura V.6

Perfil de la cara de un embrión de 12 semanas, descartándose anomalías fetales groseras.

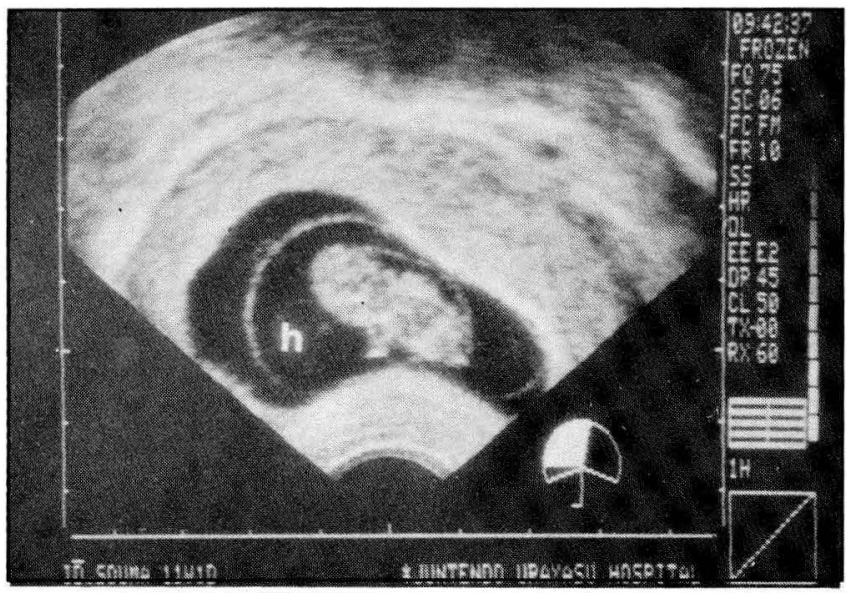

Figura V.7

Imagen de un mielomeningocele a la décima semana. (Tomado del Atlas de Assim Kurjak).

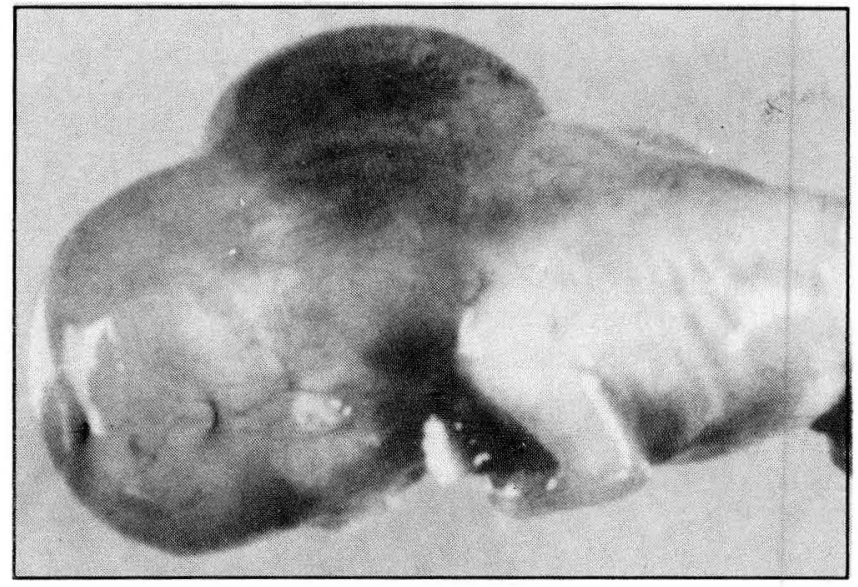

Figura V.8

Aspecto macroscópico del mismo embrión donde se apreció el mielomeningocele ecográficamente. (Tomado del Atlas de Assim Kurjak).

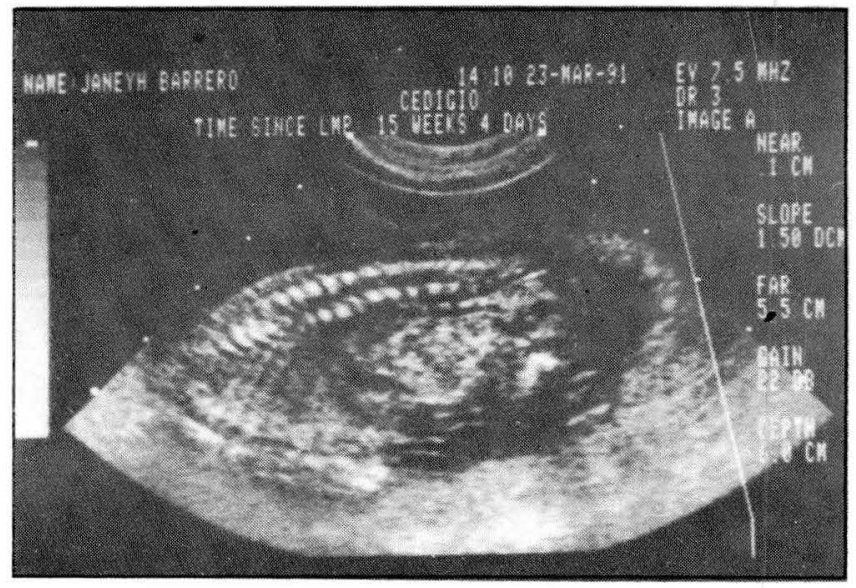

Figura V.9

Embrión de 15 semanas con una imagen completa del cierre del tubo neural descartando una alteración del mismo como el mielomeningocele.

posición intrauterina. Aún así, sólo identificando muy claramente el falo masculino se puede dar un diagnóstico de sexo, ya que la imagen que producen los escrotos son similares a la que produce la vulva (1-4).

H.-Sistema gastrointestinal: En el sistema gastrointestinal se observa una estructura hipoecoica bien delimitada por debajo del diafragma sobre el lado izquierdo del abdomen identificada ecográficamente como burbuja gástrica y que corresponde obviamente al estómago, el cual es observado a partir de la 11a semana.

Actualmente no se han reportado casos de atresias de esófago y duodeno en el primer trimestre de edad gestacional, a pesar que existen muchos reportes de extensas observaciones ultrasonográficas del primer trimestre por US endovaginal de fetos con aneupliodías confirmadas con muestreo de vellosidades coriónicas (1).

Este capítulo muestra algunas de las aplicaciones de la US endovaginal en el diagnóstico de las anomalías estructurales en el primer trimestre del embarazo. Sin embargo, se consi- 
dera que a partir de la 10-11a semana en adelante es que se pueden diagnosticar alteraciones anatómicas embrionarias, antes no (hasta ahora). Esto refleja las limitaciones de la US endovaginal en la vigilancia de la embriogénesis normal antes de la semana 10 de gestación (1).

Debido a la experiencia reciente que se tiene con este método de diagnóstico, es conveniente efectuar endosonografías seriadas antes de excluir o diagnosticar la presencia de una anomalía estructural embrionaria, estos diagnósticos se pueden apoyar en los estudios genéticos de líquido amniótico y vellosidad corial al igual que futuras observaciones ecográficas transabdominales.

Los diferentes estudios reportados en recientes publicaciones son insuficientes para permitir evaluar la sensibilidad de la ultrasonografía endovaginal en el diagnóstico de anomalías embrionarias específicas, pero se puede predecir que se podrá realizar con mayor precisión en un futuro muy próximo (1-4).

\section{La amniocentesis y la biopsia de vellosidad coriónica en el diagnóstico genético prenatal temprano}

La US endovaginal representa una gran ayuda en la técnica de la amniocentesis y de la biopsia de vellosidad corial, ya sea por punción transabdominal a mano alzada o por vía transcervical, ya que la visión que de las estructuras intrapélvicas se obtiene por endosonografía, son de una inmejorable calidad.

La amniocentesis precozen la semana 11 a 14 de gestación es un procedimiento muy controvertido, el cual está indicado en pacientes añosas, con antecedentes personales of familiares de malformaciones congénitas, en padres consanguíneos, en infecciones virales del primer trimestre temprano o cuando existen valores anormales de alfa feto proteína en suero materno.

Este es un procedimiento relativamente sencillo que con los nuevos métodos de laboratorio sólo se necesita una muestra de 5 a $10 \mathrm{cc}$ de líquido amniótico para obtener un resultado en 15 a 20 días, lo que para muchos estudiosos del tema son suficientes para el diagnóstico precoz de dichas anomalías; el procedimiento presenta en manos experimentadas una muy baja morbilidad y sólo cuando la prueba de laboratorio no es conclusiva se intentará una biopsia de vellosidad corial (7-9).

De otra parte, los detractores de la amniocentésis opinan que el diagnóstico de tales anomalías congénitas no es tan temprano como el obtenido por una biopsia de vellosidad coriónica, que dicho procedimiento no tiene la morbilidad que promulgan sus detractores y que el diagnóstico es más exacto.

La anterior controversia sumada a que estos no son procedimientos inocuos para el binomio materno fetal y que tanto en nuestra experiencia como la reportada en la literatura internacional, nos indican un porcentaje (que aunque descrito como pequeño, no está bien determinado) de pérdidas de embarazos en el primer trimestre (post-procedimiento) cromosómicamente normales (7-9), por lo tanto, debemos ser muy cautos y serenos en evaluar el verdadero costo vs beneficio al proponer estos procedimientos diagnósticos a una paciente. Obviamente estos dos procedimientos son

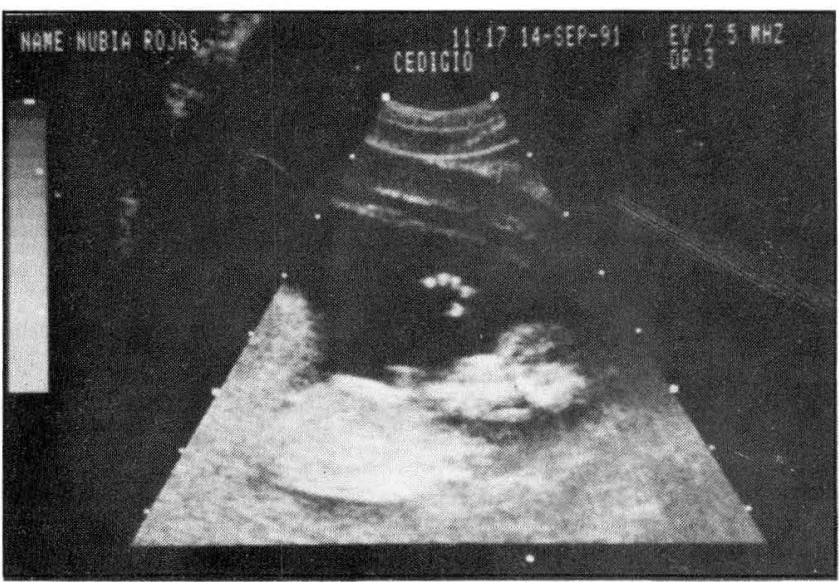

Figura V.10

Embarazo de 12 semanas con la imagen de una mano mostrando los 5 dedos.

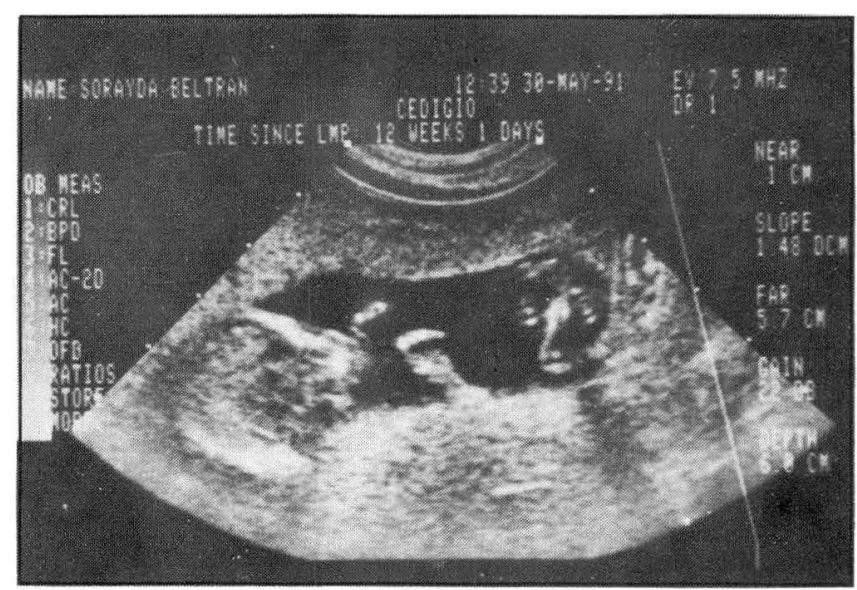

Figura V.11

Imagen de un embrión de 12 semanas con sus 4 extremidades normales y los 5 dedos de las extremidades superiores.

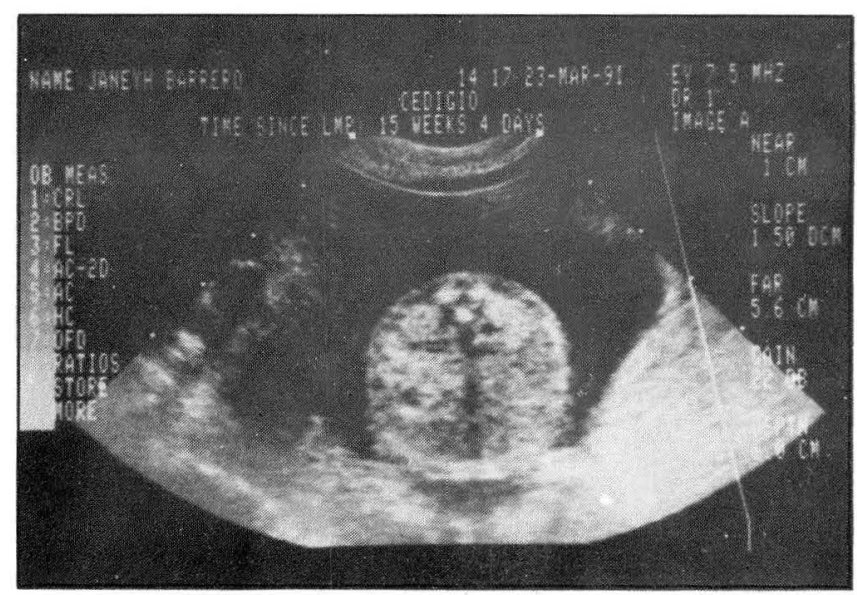

Figura V.12

Se aprecia un corte transversal del perímetro abdominal de un embrión de 15 semanas donde se observa claramente las 2 siluetas renales normales. al igual que la adecuada formación vertebral. 
alternativas muy serias y valederas para tener en cuenta en un estudio precoz de alteraciones genéticas.

\section{La US endovaginal en el diagnóstico de la incompe- tencia cervical}

El uso de la US endovaginal para la medición y análisis morfológico del cuello uterino durante el embarazo es un método relativamente nuevo. No cabe duda que la medición que se logra del cuello uterino por este método es mucho más exacta que la lograda por tacto vaginal $(1,2)$.

Además de las medidas que se han logrado estandarizar para establecer un nivel numérico predictivo de un cérvix incompetente, el análisis morfológico del cuello uterino como el acortamiento, la forma de embudo del canal endocervical con la consabida dilatación progresiva e indolora del orificio cervical interno en relación con el externo, son de un gran valor diagnóstico en la incompetencia cervical (1, 2).

En cuanto a medidas normales y anormales del cérvix vemos como varios estudios de casos y controles simultáneos en diferentes partes del mundo como Inglaterra, Alemania y EEUU principalmente, con una metodología excelente (3-6), coinciden en las siguientes conclusiones:

La extensión cervical normal de una paciente embarazada, oscila entre $46,3 \mathrm{~mm}$ y $35 \mathrm{~mm}$, pero el $85 \%$ aproximadamente se sitúa en un rango que oscila entre los $46,3 \mathrm{~mm}$ y los $39,5 \mathrm{~mm}$.

El $15 \%$ de las pacientes que son consideradas como normales presentan una extensión que oscila entre 39,5 y 35 $\mathrm{mm}$; aunque estos tienen un cuello corto no presentan incompetencia cervical y la mayoría de ellas no presentan una morfología cervical en forma de embudo; por lo tanto, deben tener un seguimiento clínico y ecográfico para estar atentos a la posibilidad de alteración morfológica cervical (tanto en forma como en tamaño), ya que en definitiva la tendencia a progresar con las modificaciones cervicales antes descritas es el dato imagenológico más importante y significativo.

La longitud cervical entre el rango de 34 y $21 \mathrm{~mm}$ según dichos estudios, es compatible casi en un $100 \%$ con un diagnóstico precoz de incompetencia cervical, el cual puede ser corroborado ulteriormente por otros métodos diagnósticos como la histeroscopía, test de dilatadores y el examen clínico.

En varios de los casos estudiados en los mencionados estudios se observó como el orificio cervical interno se dilataba progresivamente al tiempo que la morfología endocervical se volvía cónica y concomitantemente con este hecho se iban herniando las bolsas amnióticas a través del mismo hasta presentarse las manifestaciones clínicas de la enfermedad (11).

Lo anterior, sin duda, es un avance diagnóstico muy importante en obstetricia, la detección temprana de la incompetencia cervical y el establecimiento precoz de un pronóstico cervical es una ayuda invaluable en la terapéutica del problema (7).

Sin embargo, en todos estos estudios se han enfatizado que la US endovaginal es un elemento diagnóstico de mucha utilidad, el cual debe ser parte de un conjunto de exámenes paraclínicos, de un buen examen clínico de la paciente con incompetencia cervical, ya que sólo la visión global del problema puede lograr un diagnóstico y tratamiento acertado en estos casos (8).

\section{VII.Utilidad de la US endovaginal en el diagnóstico de la placenta previa}

Hasta ahora la US transabdominal ha sido el único método ultrasonográfico que se ha usado para el diagnóstico de la placenta previa. Este método a parte de ser muy útil, presenta algunos inconvenientes, entre ellos, una pobre visualización de el grado o porcentaje de compromiso del orificio cervical interno en una placenta previa parcial, la visualización deficiente en casos de placenta posterior, obesidad y de vejiga sobredistendida.

Otro inconveniente es la inexacta visualización comparativamente con la visión endovaginal del límite entre la inserción placentaria y el orificio cervical interno en una placenta previa marginal (6).

El diagnóstico falso positivo es más frecuente cuando se utiliza solamente la ultrasonografía transabdominal, lo que puede llevar a una prolongada hospitalización y/o a una innecesaria ejecución de un parto por cesárea, además de la realización de múltiples exámenes para tratar de esclarecer la sospecha de placenta previa, en dicha búsqueda se puede llegar a efectuar un examen vaginal desprevenido dando lugar a una hemorragia masiva, lo que no ocurriría con la aplicación de un transductor endovaginal ya que el rosamiento de éste con las estructuras exocervicales es nulo o prácticamente mínimo y la obtención de datos imagenelógicos es máximo (6).

Hasta hace muy poco la US endovaginal no había sido ensayada para el diagnóstico de placenta previa ya que de acuerdo con las "reglas clásicas" de la obstetricia está contraindicada la manipulación vaginal en una paciente con sospecha de placenta previa (1-3).

En la actualidad está muy claro que se puede introducir una sonda endovaginal lentamente en la vagina de una paciente con placenta previa bajo visualización sonográfica directa del cérvix, deteniéndose muy cerca $(5-10 \mathrm{~mm})$ por delante del mismo, obteniéndose de esta manera una visión muy clara de tales estructuras con una excelente zona focal que permite la obtención de imágenes diagnósticas muy exactas (1-3).

Según la experiencia de muchos autores se demuestra que la US endovaginal se puede usar para localizar con precisión la placenta previa sin causar sangrado, obviando los inconvenientes de la US transabdominal como los anteriormente descritos (1-3).

Actualmente, algunos escritores han planteado otro inconveniente de la US transabdominal frente a la endosonografía que, aunque no es muy frecuente, vale la pena mencionarlo: se trata de la presencia de una sombra acústica de la cabeza fetal en una presentación de vértice, la cual evita la localización exacta de una placenta de inserción baja $(4,5)$.

Un método sonográfico alternativo es el scanning perineal, que aunque supera alguno de los inconvenientes de la US transabdominal no logra siquiera igualar los beneficios diagnósticos que ofrece la US endovaginal porque la distancia entre el transductor endovaginal y los órganos estudiados es la más corta posible, lo que facilita una imagen inigualable 


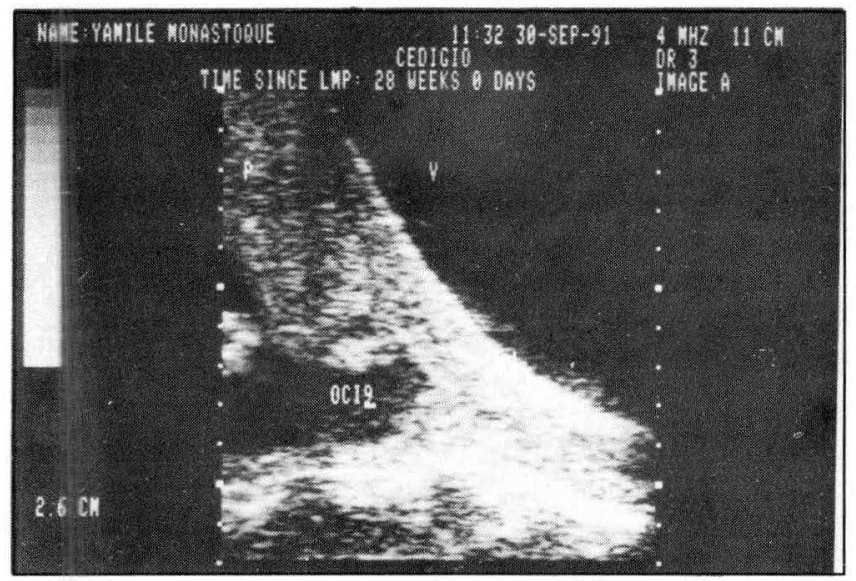

Figura VIII.1

Placenta previa marginal de un embarazo de 28 semanas, se observa el OCI, la vejiga, y la placenta de implantación baja.

por ningún otro método ultrasonográfico. Este hecho hace que la propuesta del scanning perineal no haya tenido mucha acogida (7).

Actualmente, el uso de la endosonografía secuencial permite diagnosticar con gran detalle todo el proceso de una placenta migratoria, lo cual evita la necesidad de una eventual hospitalización con múltiples ecografías transabdominales, disminuyéndose también los falsos positivos y evitando así muchas cesáreas innecesarias $(3,8)$.

Por último, se puede afirmar que la técnica de US transvaginal es un método seguro que ofrece algunos benefi-

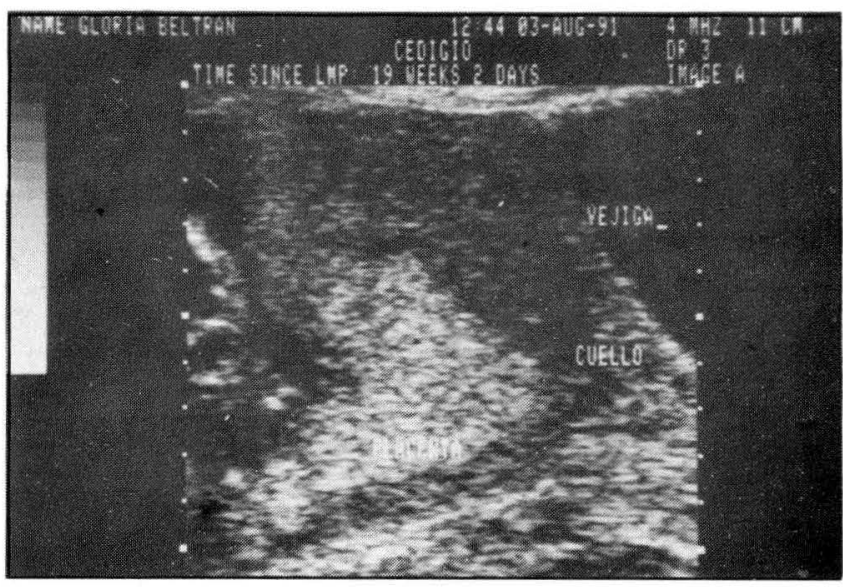

Figura VIII.2

Imagen de una placenta previa total en un embarazo de 19 semanas, tiempo en el que no se puede hacer diagnóstico definitivo por presentarse migración placentaria hasta la semana 30.

cios imagenológicos Sobre la US transabdominal en el diagnóstico de la placenta previa $(9,10)$.

Sin embargo, la forma más recomendada de estudiar ecográficamente esta patología es teniendo una visión general de la placenta, la cual se logra con un estudio ecográfico integral, conjugando la pacentografía ultrasonográfica transabdominal con la endovaginal, obteniéndose de esta forma una imagen más completa de la inserción placentaria e identificando con mayor exactitud su localización, tanto en relación con el segmento uterino inferior como con el resto del útero $(9,10)$.

\section{BIBLIOGRAFIA}

\section{PARTE I}

1. Beverly G., Coleman MD et al. TI: Transvaginal and transabdominal sonography: prospective comparation. From Department of Radiology Hospital of the University of Pennsylvania. Am. J. Radiology September 1988; 168: 639. 643.

2. Bonilla F., Musoles et al. TI: Endosonografía vaginal, sonografía transvaginal en obstetricia y ginecología. F. Bonilla-Musoles et al. Salvat 1988; 5-9.

3. Charles W., Hohler MD. TI: Estimación ultrasonográfica de la edad gestacional, St Joseph's Hospital and Med. Center, Phoenix, Arizona. Clin. Obstet. y Ginecológicas 1984; 2: 403-419.

4. Cullen MT., Green JJ. Rebeca., Hobbins JC. TI: A comparation of transvaginal and abdominal ultrasound in visualizing the first trimester conceptus. J. Ultra Sound-Med., Oct. 1989.

5. Ellen B., Mendelson MD., Marcela B., Velez MD. et al. T1: Ginecologic imaging: comparations of trans abdominal and transvaginal ultrasonography, From The Departament of Radiology and Ginecology, West Penn Hospital, Pittsburg SO: Radiology 1988; 166: 321-324.

6. James D. Bowie., Rochelle Filker Andreoti. TI: Estimación de la edad gestacional intra-útero. Ultrasonografía en Obstetricia y Ginecología. Callen-Salvat 1989; 30-40.

7. Kossoff G., TI: Current opinion on safety of diagnosis ultrasound. In Kurjak, A. Fed. Hand book of ultrasound in obstetrics and gynecology 1990; 47-53.

8. Shwiner SR., Lebovic TI: Transvaginal pelvic ultrasonography. J. Ultrasound Med. 1984; 3: 381-383.
9. Timor-Tritsch IE., Bartfai Kaali SG., et al. TI: Vaginal ultrasonography: a new testing method in obstetrics and gynecology. SO: Orv-Hetil; Jun 4; 1989; 130: (23).

10. Kurjak A., Zalud I. Uterine Masses. Chapter 12 p: 123-134, Text book: Transvaginal Doppler Color, publishing in the USA by The Parthenon Publishing Group Inc. 1991.

11. Bruno D., Fornage MD., Frank O'keeffe, MD. TI: Ultrasoundguied transvaginal biopsy of malignant cystic pelvic masses. J. Ultrasound Med. 1990; 9: 53-55.

12. M. Hellen Rodriguez. Md. et al. TI: The use of transvaginal sonography for evaluation of postmenopausal ovarian size and morphology. Am. J. Obstet-Gynecol. 1988; 810-813.

\section{PARTE II}

1. Bateman BG., Nunley WC. Jret al. TI: Vaginal sonography finding and HCG dynamics of early intrauterine and tubal pregnancies. Obstet. Gynecol. 1990; Mar; 75 (3 pt 1): 421-427.

2. Bernaschek G., Rudelstofer et al. TI: Vaginal sonography VS. HCG seric in early detection of pregnancy. Am. Journal of Obstetrics and Gynecology. 1988; 158 (3 pt 1).

3. BT. Haylen., MI. Fraizer., JR. Sutherst et al. TI: Transvaginal ultrasound in the assessment of bladder volumes in women. British Journal of Urology 1989; 63: 149-151.

4. David A.. Nyberg MD., Laurance A., Mack MD. et al. TI: Early pregnancy complications; endovaginal sonographic Finding Correlated with HCG Levels. Radiology 1988; 167: 619-22. 
5. Granber S., Wikland M. et al. TI: Macroscopic characterization of ovarian tumors and the relation to the histological diagnosis: criteria to be used for ultrasound evaluatio. SO: Gynecol.-oncol. 1989; Nov. 35(2): 139-144.

6. Higgins RV., Van Nagell $\mathrm{J}_{\mathrm{r}}$ et al. TI: Transvaginal sonography as a screening method for ovarian cancer SO: Gynecol.-Oncol. 1989; Sep. 34; 34 (3): 402-406.

7. Klug PW., Leitnerg et al. TI: Comparation of vaginal ultrasound and histologic findings of the endometrium. SO: geburts hilfeFravenheilkd: 1989; Sep. 49 (9): 797-802.

8. MJ Quinn., J. Beynon NN., McC Mortensen et al. TI: Vaginal endosonography in the post-operative assessment of colposuspension. British Journal of Urology 1989; 63: 295-300.

9. Novack-Antolic et al. TI: Incorporating endovaginal us in to the over all gynecologic examination. SO: Am. J. Obst. Gynecol. 1990; 162 (3): 625-632.

10. Osmers R., Volkesen M., et al. TI: Vaginosographic detection of endometrial cancer in post menopausal women; SO: Int-j-Gynecol.Obstet. 1990; May. 32 (1): 35-37.

11. Peisner DB., Timor-Tritsch et al. TI: The discriminatory zone of BHCG for vaginal Probes JCU. 1990; May 18 (4): 280-285.

12. Rodriguez MH., Platt LD. et al. TI: The use of transvaginal sonography for evaluation of postmenopausal ovarian side and morphology SO: Am. J. Obstet.-Gynecol. 1988; Oct. 159 (4): 810-814.

13. Ellika Andolf MD., Connie Jorgensen MD. et al. A prospective comparation of transabdominal and tranvaginal ultrasound with surgical findings in gynecologic disease. J. Ultrasound 1990; 9: 7175.

14. Bruno D., Fornage MD., Frank O'keeffe, MD. TI: Ultrasoundguied transvaginal biopsy of malignant cystic pelvic masses. J. Ultrasound Med. 1990; 9: 53-55.

15. Kurjak A. Zalud I. Uterine Masses. Chapter 12 p. 123-134, Text book: Transvaginal Doppler Color, publishing in the USA by The Parthenon Publishing Group Inc. 1991.

16. Kurjak Assim and H. Shulman. TI: Anexial masses. Chapter 11 p. 103-122. Text book: Transvaginal Doppler Color, publishing in the USA by The Parthenon Publishing Group Inc. 1991.

17. M. Hellen Rodriguez., MD. Lawrance D., Platt MD., et al. TI: The use of transvaginal sonography for evaluation of postmenopausal ovarian size and morphology. Am. J. Obstet.-Gynecol. 1988; October 810813.

\section{PARTE III}

1. Beverly G., Coleman MD et al. TI: Transvaginal and transabdominal sonography: prospective comparation. From Department of Radiology Hospital of the University of Pennsylvania. Am. J. Radiology 1988; September 168: 639, 643.

2. Lachlan $\mathrm{CH}$. de Crespigny MD et al. TI: Early diagnosis of pregnancy failure with transvaginal ultrasound. Am. J. Obst.-Gynecol. 1988; 159: 408-409.

3. De Crespigny LC.. Cooper D. et al. TI: Early detection of intrauterine pregnancy with ultrasound. J. Ultrasound-Med. 1988; Jan 7 (1): 7-10.

4. Ruth B., Goldstein MD. TI: Endovaginal sonography in very early pregnancy: new observations. Radiology 1990; 176: 7-8.

5. Bernaschek G., Rudelfoster et al. TI: Vaginal sonography VS, HCG seric in early detection of pregnancy. Am Journal of Obstetrics and Ginecology, 1988; March 158: (3 pt 1).

6. Sydow P., Lisse K., Wilken T., Pfuller B. TI: Vaginal sonography in the diagnosis of early pregnancy. Zentralbl-Gynakol. 1989; 111 (7): 453-460.

7. G. Grvenkovic A., Kurjak H., Takeuchi. TI: Assessment of early pregnancy. Chapter 5. p. 41-51. Text book; TRansvaginal Doppler Color, publishing in the USA by The Parthenon Publishing Group Inc. 1991

8. Cullen MT., Green JJ., Reece EA., Hobbins JC. TI: A comparison of transvaginal and abdominal ultrasound in visualizing the first trimester conceptus. J. Ultrasound-Med. 1989; 8 (10): 565-569.

9. Clifford S., Levi MD., Edward A., Lyons MD et al. TI: Ednovaginal VS: Demostration of cardiac activity in embryos of less than $5.0 \mathrm{~mm}$. In Croan-Rump length. Radiology. 1990; 176: (71-74).

10. Clifford S., Levi MD., Edward A., Lyons MD. et al. TI: Early diagnosis of nonviable pregnancy with endovaginal US. Radiology. 1988; 167 : 383-385.
11. Soregi G. MD., Reinold E. MD., TI: Early diagnosis of pregnancy failure with to ultrasound. Am. J. Obstet. and gynecol. 1988; 159 (2): 408-409.

12. Fendel H. MD., et al. TI: Very early diagnosis of pregnancy fairlure with ultrasound. Am. J. Obstet. Gynecol. Am. J. Obstet. Gynecol. 1988; 158: (3 pt1) 608-612.

\section{PARTE IV}

1. Mahox John H. MD., et al. TI: Heterotopic pregnancy diagnosed by endovaginal scanning. J-din ultrasound 1989; 17: 523-526.

2. Steven R., Goldstein MD., John RR., Snyder MD., et al. TI: Very early pregnancy detection with endovaginal ultrasound. Obstetrics \& Ginecology. 1988; 72 (2): 200-204.

3. Nyberg A., David et al. TI: Early pregnancy complications: endovaginal sonographic findings correlated with human chorionic gonadotropin levels. Radiology 1988; 167: 619-622.

4. Bruno Cacciatore MD., et al. TI: Comparation of abdominal and vaginal sonography in suspected ectopic pregnancy. Obstet. Gynecol. 1990; 73: 770-774.

5. Peisner DB., Timor-Tritsch et al. TI: The discriminatory zone of BHCG for vaginal probes. JCU. 1990; 18 (4): 280-285.

6. Stabile I., Campbell S. et al. TI: Can ultrasound realiably dignose ectopic pregnancy ? Br.-J.-Obstet.-Gynecol. 1988; 95 (12): 1247 1252.

7. Arthur C. Fleischer., Peter S., Cartwright Rebeca G., Pennell et al. TI: Sonography of ectopic pregnancy with transabdominal and transvaginal scanning. The principles and practice of ultrasonography in obstetric and gynecology (Text Book), Chapter five, Fourth Edition. Apleton and lange. 1991.

8. Shurz B. et al. TI: Early diagnosis of tubal pregnancy with vaginal sonography. Geburtshilfe-Fravenheilkd. 1989; 49 (7): 649-652.

9. Rosati P., Noia G. et al. TI: Use fulnes and limits of the ultrasonic examination in the diagnosis and pregnosis of early pregnancies with vaginal bleeding. Minerva-Gynecol. 1989; 41 (10): 485-488.

10. Lachaln $\mathrm{CH}$., de Crespigny MD. TI: Early diagnosis of pregnancy fairlure with transvaginal ultrasound. Am. J. Obstet. Gynecol. 1988; 159: 408-410.

11. Bonilla-Musoles F., Pardo G., Pérez-Gil et al. TI: Endosonografía vaginal en el primer trimestre del embarazo normnal y patológico. Ultrasonidos, SOCOUM March 1990; 1: 16-23.

12. Timor-Tristsch IE., Rottem S. TI: Transvaginal ultrasonographic study of the fallopian tube. Obstet. Gynecol. 1987; 70: 424-428.

13. Loong EPL., Lee HC. TI: Transvaginal ultrasonography imaging ectopic pregnancy. Aust. N. Z. Obstet. Gynecol. 1988; 27: 346-348.

14. Leeton J. Davidson G. TI: Nonsurgical Management of un ruptered tubal pregnancy with intra amniotic methotrexate: preliminary report of two cases. Fertil-Steril. 1988; 50 (1): 176-179.

15. Pilka L., Texl P., Vesely J. et al. TI: Aspiration of a gestacional SAC controlled by vaginal ultrasound in multiple pregnancy for the purpuse of selective abortion. Zentralbl-Gynecol. 1990; 112 (13): 849-852.

16. Ribic-Pucelj M., Novaj-Antolic Z et al. TI: Treatment of ectopic pregnancy with prostaglandin E2. Clin.-Exp.-Obstet.-Gynecol. 16 (4): 106.

17. Hinds LA., Tyndale-Biscoe CH., Shaw G. et al. TI: Effects of prostaglandin nad prolactin on luteolysis and parturient behaviour in theh non-pregnant tammar, macropus eugenii. J. Reprod.-Fertil. 1990: 88 (1): 323-333.

18. Howard HJ., Britt JH. TI: Prostaglandin F-2 alpha causes regression of an HCG-induced corpus luteum before day 5 od its lifespan in cattle. J.-Reprod.-Fertil 1990; 90 (1): 245-253.

19. Roseff SJ., Kettel LM., Rivier J. TI: Accelerated dissolution of lutealendometrial integrity by the administration of antagonists of gonadotropin-releasing hormone and progesterone to late-lvteal phase women. Fertil-Steril. Nov. 1990; 54 (5): 805-810.

20. Ron-El R., Golan A., Herman A. et al. TI: Midluteal gonadotropinreleasing hormone analog administration in early pregnancy. FertilSteril. Mar 1990; 53 (3): 572-574.

21. Herbert C., Fleisher A. et al. TI: Ectopic pregnancy: features of transvaginal sonography. Radiology. 1990; 174: 375-378.

22. Kunk A. et al. TI: The use of a vaginal probe in the diagnosis of ectopic pregnancy. Arch.-Gynecol.-Obstet. 1989; 244 (3): 163-168. 
23. Arthur C. Fleischer., Alan N., Gordon et al. Sonography of trophoblastic diseases. The principles and practice of ultrasonography in obstetric and ginecology (Text Book), Chapter Thirty-one, Fourth Edition. Apleton and lange. 1991.

24. Ansbacher R., Hopkins MD et al. TI: Localization of trofoblastic disease with vaginal ultrasonography. J-Report-Med. Aug. 1990; 35 (8): 835-838.

25. Romero R., Fisher N., et al. TI: First trimester diagnosis of a partial mole with the combined use of ultrasound and chorionic villous sampling. Am. J. Perinatol. 1989; 6 (3): 314-316.

26. Bateman BG., Nunley WC Jr et al. TI: Vaginal sonography finding and HCG dynamics of early intrauterine and tubal pregnancies. Obstet. Gynecol. 1990; 75 (3 pt 1) 421-427.

27. Timor-Tritsch IE. et al. TI: Vaginal ultrasonography: a new testing method in obstetric and ginecology. Orv. Hetil. Jun. 1989; 4: (130) 23.

28. Fendel H. MD. et al. TI: Very early diagnosis of pregnancy fairlure with ultrasound. Am. J. Obstet. Gynecol. 1988; 158 (3 pt 1) 608-612.

\section{PARTE V}

1. Mark T., Cullen MD., Jaqueline Green et al. Transvaginal ultrasonographic detection of congenital anomalies in the first trimestres. Am. J. Obst.-Gynecol. 1990; 163: 466-476.

2. Green JJ., Hobbins JC. TI: Abdominal ultrasound examination of the first-trimestrer fetus. Am Journal Obst.-Gynecol. 1989; 159: 163-175.

3. Cullen MT., Green JJ. et al. TI: Evaluation of the first trimester embryo. A comparison of transvaginal and abdominal sonography J.Ultrasound Med. 1990; 8: 565-569.

4. Rottem S., Broushtein M. et al. First trimester transvaginal sonographic diagnosis of fetal anomalies. Lancet. 1989; 1: 444-445.

5. Gray DL., Martin CM., Grange JP. TI: Diferencial diagnosis of first trimester. Uretral Wall Defect. J.-Ultrasound Med. 1989; 8: 255-258.

6. Bronshtein M., Zimmer EZ. MD. TI: Transvaginal ultrasound diagnosis of fetal clubfeet at 13 weeks, menstrual age. J. Clin. Ultrasound. 1989; 17: 518-520.

7. Karin J., Blackmore MD. Diagnóstico prenatal mediante biopsia de vellosidades cariónicas. Temas actuales de Gineco-Obst. 1988; 2: 179-213.

8. Poppl W. et al. TI: The role of transvaginal sonography in chorionic villi sampling. JCU. 1990; 18: 315-322.

9. Berly R., Banacerraf MD et al. Amniocentesis precoz para evaluación citogenética prenatal. SOCOUM (Sociedad Colombiana de Ultrasonidos). Mar. 1990; 3-10.

10. Kushnir O., Izquierdo L. et al. TI: Early transvaginal sonographic diagnosis of gastroschisis. Y. Clin. Ultrasound. 1980; 8, 217.

\section{PARTE VI}

1. Zemlyn S. TI: The length of the uterine cervix and its significan. J. Clin. Ultrasound 1981; 9: 267 .

2. Bernstine RL., Lee SH. et al. TI: Sonographic evaluation of the incopetent cervix J. Clin. Ultrasound 1981; 9: 417.
3. Balde MD., Stalz W., Unteregger et al. TI: Transvaginal echography and application in the diagnosis of cervical incompetence. J.-Gynecol.Obstet.-Biol.-Repord (Paris) 1988; 629-633.

4. Chapple CR., Helmew et al. TI: Asymptomatic bladder neck incompetence in multiparous females. Br.-J.-Urol. 1989; 357-359.

5. Stolz W., Balde MD. et al. TI: Evaluating the cervix in pregnancy using vaginal sonography. Studies of cervix insufficiency. GeburthshilfeFravenheilkd. 1989; 1063-1066.

6. Brown J., Shalh D., Thieme G. et al. TI: Evaluation of the cervix with transabdominal and transvaginal US. Am. J. Obst.-Gynecol. 1988; 721-726.

7. Faye C. Laing. TI: Ultrasound evaluation of obstetric problems relating to the lower uterine segment and cervix. Aplethon and lange ecographyc report. Chapter 30, Jan. 1991.

8. Chryssikopoulos A., Botsis D. et al. TI: Cervical incompetence: A 24 years review. Gynecol. Obstet. April 1988; 245-253.

9. Parulekar SG., Kiwi R. TI: Ultrasound evaluation of sutures following cervical cerclage for incompetent cervix cervix uteri. J. Ultrasound. Med. 1982; 1: 223

10. Arias F. TI: Cervical cerclaje for the temporary treatment of patients with placenta previa. Obstet.-Gynecol. April 1988; 71 (4): 545-548.

11. Sarti DA., Soumple WF. et al. TI: Ultrasonic visualization of a dilate cervix during pregnancy. Radiology 1979; 130: 417.

\section{PARTE VII}

1. Farine D., Fox HC., Jakobson S. et al. TI: Vaginal ultrasound for diagnosis of placenta previa. Am.-J.-Obstet.-Gynecol. 1988; 566-569.

2. Farine D., Fox HC., Jakobson S. et al. TI: Is it really placenta previa ? Eur. J. Obst.-Gynecol. Reprod. 1989; 31: 103-108.

3. Robert A., Leerentveld MD. (Phd)., et al. TI: Accuracy and safety of transvaginal sonographic placental localization: Obstetrics and Gynecology 1990; 76: 759-761.

4. Laingfe et al. TI: Placenta previa: False negative diagnoses J.C.U. 1981; 9: 109.

5. Bowie JD., Rochester D. TI: Acurracy of placental localization by ultrasound. Radiology 1988; 177-180.

6. Gottesfeld KR., Thompson HE. et al. TI: Ultrasonic placentography a new method for placental localization. Am. J.-Obstet.- Gynecol. 1986; 96: 538.

7. Mihelstaedt CA., Partain CL., et al. TI: Placenta previa: Significance in the second trimester. Radiology. 1979; 131: 465.

8. Lavery-JP. Michigan State University. TI: Placenta previa. Clin.Obstet.-Gynecol. 1990; 414-421.

9. Meclure N., Dornal-J. et al. TI: Early identification of placenta previa. Br.-Obstet.-Gynecol. 1990; 97 (10): 959-961.

10. Fayes C. Laing. TI: Ultrasound evaluation of obstetric problems relating to the lower uterine segment and cervix. Textbook: Transvaginal Doppler Color, publishing in the USA by the Parthenon Publishing Group Inc. Chapter 30, 1991; 487-499. 